\title{
A Prediction Model of Forest Preliminary Precision Fertilization Based on Improved GRA-PSO-BP Neural Network
}

\author{
Chen Zuxing ${ }^{1,2}$ and Wang Dian ${ }^{1}{ }^{1}$ \\ ${ }^{1}$ College of Engineering, Beijing Forestry University, Beijing 100083, China \\ ${ }^{2}$ Liupanshui Normal University, Liupanshui 553004, China \\ Correspondence should be addressed to Wang Dian; wangdian@bjfu.edu.cn
}

Received 20 March 2020; Revised 20 July 2020; Accepted 7 August 2020; Published 27 August 2020

Academic Editor: Pietro Bia

Copyright (c) 2020 Chen Zuxing and Wang Dian. This is an open access article distributed under the Creative Commons Attribution License, which permits unrestricted use, distribution, and reproduction in any medium, provided the original work is properly cited.

\begin{abstract}
The optimal amount of fertilizer application which was needed by the trees and the factors that influence the fertilization have an intricated nonlinear relationship. According to the problems that the traditional fertilization prediction model has, such as lacking of the scalability and practicality, this paper initiates an accurate fertilization prediction model that was based on the GRA-PSOBP neural network which can make the accurate fertilization come true and improve the economic benefits of forest industry. This paper uses the GRA method to determine the input of the neural network as the site index and make the forest age, nutrient content of the advantage trees, biomass of the advantage trees, biomass of average trees, and target yield as the output numbers of the Actual amount of fertilizer applied. During the calculation process, the global particle swarm optimization algorithm is used to optimize the initial numbers and threshold numbers of BP neural network which build a phased GRA-PSO-BP accurate fertilization model. Compared with the prediction algorithm of full input variate that is based on the single BP neural network and the prediction algorithm of full input variate that is based on PSO-BP Neural Network, the GRA method can determine the key factors that influence the amount of fertilizer applied in different forest areas and modify the prediction model to improve the scalability and accuracy of the prediction and finally achieve the precision fertilization as the data of different forests updated, so we can see that the prediction result of this paper is more accurate. The result demonstrates that the GRA-PSO-BP neural network Segment fertilization model is more accurate than the traditional BP neural network and BP Neural Network that was optimized by the PSO algorithm, and specifically, the error of the predicted amount of fertilizer application and the actual amount of fertilizer application is less than $5 \%$, which can effectively guide the fertilization in stages.
\end{abstract}

\section{Introduction}

In the process of forestry production, it is fundamentally required to calculate the amount of fertilizer, such as nitrogen, phosphorus, and potassium fertilizer, for different forest species and different soil conditions [1]. Cunninghamia lanceolata enjoys the characteristics of fast growth, wide application, high economic value, and easy reproduction [2]. Cunninghamia lanceolata is dependent on fertilizer and humidity. In the condition of $25^{\circ} \mathrm{C}-35^{\circ} \mathrm{C}$, Cunninghamia lanceolata can grow rapidly. In this regard, fertilization is the key link for high yield of Chinese fir forest. Fertilization generally applies from young forest to middleaged forest, which plays an important role in forestry economy. Forest fertilization functions as a critical technique to enhance soil fertility, improve tree nutrition, and facilitate rapid growth and high yield [3, 4]. At present, forestry production is increasingly transformed to precision operations. Cunninghamia lanceolata production is no exception. The premise of precision production of Chinese fir forest is precise fertilization since such an agrotechnique can help balance the nutrients in soil and increase the nutrients required by trees, so as to achieve the target yield. In addition, the implementation of precision fertilization can save the fertilizer and phase down environmental pollution.

Fertilization prediction model, as the key of precision fertilization in Cunninghoya lanceolata forest, has become a hot spot in forestry research. In response to this issue under 
discussion, Hu Yueli et al. proposed a site-nutrient effect fertilization model [5-9]. However, sometimes this model can hardly help to get satisfactory accuracy and stability. The traditional fertilization model can only describe the static relationship between the growth of forest and the required fertilization nutrients, which can hardly reflect the different growth periods of trees. In view of the differences in nutrient absorption capacity and fertilizer application in different growth stages, this model cannot be applied to guide the stage fertilization of trees. In the past, it was difficult to collect data due to the long growth period of forest. Therefore, there were few models of forest fertilization. However, in recent years, sensor network can be used to collect real-time data in forest areas with the burgeoning development of artificial intelligence. It is time to construct a predictive model of accurate fertilization of forest through the collected data. Similarly, as the traditional one, the model can only exert real-time and accurate small-scale prediction in forest areas considering the complexity of different forest areas and site indices, the diversified factors affecting forest fertilization. At the same time, since there is a high degree of nonlinearity between site index and dominant wood-related nutrient content, forest age, and other influencing factors, the traditional fertilization model often has inaccurate results due to manifold parameters or low goodness of fitting. As a result, the large amount of accumulated data can hardly serve to guide production practice. In the later stage, expert experience is still needed, resulting in a waste of manpower, material, and financial resources.

Neural network is considered to be a powerful tool to solve nonlinear problems [10-15]. In order to ensure the integrity of information and improve the precision of fertilization prediction, the prediction model of multifactor precision fertilization based on neural network can be used to solve these problems. It can reflect different absorption of nutrients in different growth periods of young and middle ages of trees and apply fertilizer efficiently in the optimal fertilization period of trees. The BP algorithm shows great potential to introduce the prediction model of forest fertilization. With the updating of the data of forest fertilization experiment, the $\mathrm{BP}$ algorithm modifies the existing prediction model of fertilization, which makes the forecasts of the model more precise and get closer to the actual situation. However, the accuracy of predicted results and actual values is not fairly reliable, on account of some big defects, such as local optimization, slow convergence speed, and large dependence on training data, when a single BP neural network algorithm is used to predict the amount of fertilizer applied to trees. In this paper, the analyzing method of grey relativity [16-19] is introduced to extract the original variable data of multiple indexes in advance, and the factors with high correlation degree are taken as the network input layer, and then the global searching ability of PSO [20-25] is used to optimize the BP neural network, which greatly avoids the defect of the model falling into the local optimum and further improves the accuracy. Although neural network prediction has been applied in medical engineering, electric power, system, and other fields at home and abroad, and some gratifying results have been achieved, there are only few studies on the application of neural network prediction model to forest fertilizer application. Therefore, an improved GRA-PSO-BP algorithm was used to establish the accurate fertilization model of trees in stages.

\section{Methodology}

2.1. Test Area Overview and Plot Settings. The experimental data are from the state-run forest farm in Renhua County, Guangdong Province, and Liujiashan Forest Farm in Shixing County, Guangdong Province, which is the main production area of fir trees, with an altitude of less than $500 \mathrm{~m}$, and the soil type is the red and yellow soil developed on slates. Largescale fertilization experiments were carried out for young and mature timber of fir forests, and the experimental forests with different site indexes were classified during the experiment according to the utilization of the last round of forest land and the Nanling Mountains fir trees in the different site conditions; the experimental forest can be divided into four types: (1) triple-tilled woodlands of Cunninghamia lanceolata, with a site index of 5; (2) cultivated Chinese fir double-tilled woodlands of Cunninghamia lanceolata, with a site index of 18; (3) first ploughing woodlands after shrub felling, with a site index of 21; and (4) first ploughing woodlands after logged broad-leaf forests, with a site index of 23 . Under the condition of the same site index, the slope direction of the test site is the same, the terrain difference is small, and the trees are arranged at the same height. The young forest and the middle-aged forest test area are, respectively, set in the forest stands with appropriate site index, and the area of each test site is $1 \mathrm{hm}^{2}$. The initial planting density of young trees in the experimental forests was 3,600 plants $/ 1 \mathrm{hm}^{2}$. In the first 6 to 8 years, the first thinning was carried out, and the forests in the middle-aged forests were retained at $2,700 \mathrm{plants} / \mathrm{hm}^{2}$. The size, distribution, and density of the forests in each experimental area were basically the same. There are fixed stakes around each test area, and the dominant wood and average wood in the test area have specific numbers. The growth and nutrient dynamics of dominant wood and average wood in the test area are measured regularly every year, and nitrogen, phosphorus, and potash fertilizers are applied according to the fertilization method in the test area.

16 plots with age of $5 a, 19 a, 22 a$, and $25 a$ were selected in the above four different site types. The selected average and dominant trees in different areas were logged and then divided by leaves, branches, stems, barks, and roots to weigh each organ of them. The age of leaves and branches were weighed, respectively, and the root system was dug to a depth of $60 \mathrm{~cm}$ in the range of the canopy. Samples of all organs were evenly sampled and dried at $80^{\circ} \mathrm{C}$ to determine water and nutrient content. Meanwhile, four soil sampling points of different stand ages were set up in four different site index types, 16 soil sampling points in total. Take soil samples in $0 \sim 60 \mathrm{~cm}$ soil layer of each soil sampling point. The physicochemical analysis of plant and soil samples was carried out in accordance with conventional methods, and the determination of the physicochemical properties of the soil in the experimental forest land is shown in Table 1. 
TABle 1: Test results of physical and chemical properties of the soil of experimental forest land.

\begin{tabular}{|c|c|c|c|c|c|c|c|c|}
\hline $\begin{array}{l}\text { Stand age } \\
(\mathrm{t} / a)\end{array}$ & $\begin{array}{c}\text { Site } \\
\text { index } S\end{array}$ & Texture & $\begin{array}{l}\text { Organic matter } \\
\left(\mathrm{g} / \mathrm{kg}^{-1}\right)\end{array}$ & $\begin{array}{l}\text { Total nitrogen } \\
\left(\mathrm{g} / \mathrm{kg}^{-1}\right)\end{array}$ & $\begin{array}{c}\text { Fast-acting } \\
\text { nitrogen }\left(\mathrm{mg} / \mathrm{kg}^{-1}\right)\end{array}$ & $\begin{array}{c}\text { Fast-acting } \\
\text { phosphorus }\left(\mathrm{g} / \mathrm{kg}^{-1}\right)\end{array}$ & $\begin{array}{c}\text { Fast-acting } \\
\text { potassium }\left(\mathrm{g} / \mathrm{kg}^{-1}\right)\end{array}$ & $\mathrm{PH}$ \\
\hline \multirow{4}{*}{$5 a$} & 5 & $\begin{array}{c}\text { Middle } \\
\text { soil }\end{array}$ & 9.0 & 0.3 & 16 & 2.1 & 57 & 4.6 \\
\hline & 18 & $\begin{array}{c}\text { Middle } \\
\text { soil }\end{array}$ & 17.4 & 0.89 & 27.7 & 3.0 & 80 & 4.9 \\
\hline & 21 & $\begin{array}{c}\text { Middle } \\
\text { soil }\end{array}$ & 22.0 & 1.12 & 32 & 4.0 & 92 & 5.0 \\
\hline & 23 & $\begin{array}{c}\text { Middle } \\
\text { soil }\end{array}$ & 27.0 & 1.35 & 48 & 5.0 & 100 & 5.2 \\
\hline \multirow{4}{*}{$19 a$} & 5 & $\begin{array}{l}\text { Middle } \\
\text { soil }\end{array}$ & 8.9 & 0.32 & 16.4 & 2.3 & 54 & 4.5 \\
\hline & 18 & $\begin{array}{c}\text { Middle } \\
\text { soil }\end{array}$ & 17.2 & 0.9 & 28 & 3.1 & 88 & 4.8 \\
\hline & 21 & $\begin{array}{c}\text { Middle } \\
\text { soil }\end{array}$ & 22.1 & 1.14 & 32 & 4.1 & 90 & 5.1 \\
\hline & 23 & $\begin{array}{c}\text { Middle } \\
\text { soil }\end{array}$ & 27.3 & 1.38 & 47.6 & 5.0 & 96 & 5.3 \\
\hline \multirow{4}{*}{$22 \mathrm{a}$} & 5 & $\begin{array}{c}\text { Middle } \\
\text { soil }\end{array}$ & 9.0 & 0.31 & 16.1 & 2.2 & 52 & 4.4 \\
\hline & 18 & $\begin{array}{l}\text { Middle } \\
\text { soil }\end{array}$ & 17.1 & 0.87 & 28.1 & 3.2 & 91 & 4.7 \\
\hline & 21 & $\begin{array}{c}\text { Middle } \\
\text { soil }\end{array}$ & 22.0 & 1.11 & 32 & 4.2 & 87 & 5.4 \\
\hline & 23 & $\begin{array}{c}\text { Middle } \\
\text { soil }\end{array}$ & 27.1 & 1.33 & 48.1 & 5.2 & 94 & 5.1 \\
\hline \multirow{4}{*}{$25 \mathrm{a}$} & 5 & $\begin{array}{c}\text { Middle } \\
\text { soil }\end{array}$ & 9.1 & 0.3 & 16.2 & 2.0 & 55 & 4.8 \\
\hline & 18 & $\begin{array}{c}\text { Middle } \\
\text { soil }\end{array}$ & 17.3 & 0.91 & 28.2 & 3.0 & 83 & 4.9 \\
\hline & 21 & $\begin{array}{c}\text { Middle } \\
\text { soil }\end{array}$ & 22.2 & 1.10 & 32 & 4.3 & 91 & 5.3 \\
\hline & 23 & $\begin{array}{c}\text { Middle } \\
\text { soil }\end{array}$ & 27.0 & 1.36 & 47.9 & 5.1 & 100 & 5.1 \\
\hline
\end{tabular}

The discrepancies of site level are due to the different locations of the samples, which results in different climatic zones, slopes, slope positions, and soil types. The differentiated use of forest land at different site levels leads to significant differences in the organic matter content, nutrient content, and fertilizer utilization rate of the humus layer in the woodlands. Consequently, it can be concluded that the availability of soil nutrients is one of the essential factors for different experimental forests.

In the selection of the test plots, the age of the forest stands has been replaced by space instead of time. The accuracy of analysis is, to some extent, affected by the varied environmental conditions between the dominant wood and the average wood in the same site type. However, the effects of random errors on the basic trend of tree growth and nutrient absorption changing with forest age were relatively eliminated due to the significant difference between the growth of dominant and average stands.

2.2. Variation of Nutrient Content in Organs of Cunninghamia lanceolata. Table 2 shows the measured values of nitrogen $(\mathrm{N})$, phosphorus $(\mathrm{P})$, and potassium $(\mathrm{K})$ in different organs of dominant Chinese fir trees. The nutrient content of different Chinese firs varies greatly. The order of nutrient content in the various parts of the tree is as leaf, branch, bark, root, and stem. At the same time, it was also shown that the nutrient contents of different organs of Cunninghamia lanceolata with different site indexes were different at different ages. The content of nitrogen in the leaves increased with the increase of the site index and the age of the forest; the content of potassium in the leaves, nitrogen, phosphorus, potassium in the trunk, branches, and bark and the content of the phosphorus and potassium in the roots decreased with the increase of the age.

Table 3 shows the biomass range from average tree to dominant tree and the percentage of each organ in Chinese fir forest. Based on the data in Tables 2 and 3, the average nutrient content $C$ of the Chinese fir forest obtained by the weighted average method is calculated as $C=\left(\sum C_{i} w_{i}\right) / \sum w_{i}$, where $C_{i}$ and $w_{i}$ represent the nutrient content and biomass of leaves, branches, stems, bark, and roots of a single tree, respectively. Its product sum $\sum C_{i} w_{i}$ is the total amount of nutrients absorbed by a single tree, the total organ biomass $\sum w_{i}$ is the total biomass of a single tree, and the relationship between the total nutrient absorption $X$ 
TAвLE 2: Nutrient content of dominant Chinese fir of different forest ages under different site conditions, g/kg.

\begin{tabular}{|c|c|c|c|c|c|c|c|c|c|c|c|c|c|}
\hline \multirow{3}{*}{ Organ } & \multirow{3}{*}{ Stand age $(t / a)$} & \multicolumn{4}{|c|}{ Nitrogen } & \multicolumn{4}{|c|}{ Phosphorus } & \multicolumn{4}{|c|}{ Potassium } \\
\hline & & \multicolumn{4}{|c|}{ Site index $S$} & \multicolumn{4}{|c|}{ Site index $S$} & \multicolumn{4}{|c|}{ Site index $S$} \\
\hline & & 5 & 18 & 21 & 23 & 5 & 18 & 21 & 23 & 5 & 18 & 21 & 23 \\
\hline \multirow{4}{*}{ Leaf } & 5 & 6.8 & 10.7 & 12.6 & 13.8 & 0.75 & 1.02 & 1.09 & 1.12 & 3.2 & 4.7 & 4.9 & 5.0 \\
\hline & 19 & 8.6 & 12.1 & 12.4 & 12.7 & 0.84 & 1.16 & 1.28 & 1.06 & 3.3 & 4.3 & 4.7 & 4.9 \\
\hline & 22 & 9.4 & 13.2 & 13.5 & 13.7 & 0.91 & 1.12 & 1.25 & 0.93 & 3.4 & 4.2 & 4.6 & 4.8 \\
\hline & 25 & 10.1 & 13.9 & 14.1 & 14.2 & 0.92 & 1.04 & 1.07 & 0.97 & 3.2 & 4.1 & 4.5 & 4.7 \\
\hline \multirow{4}{*}{ Branch } & 5 & 3.9 & 6.7 & 7.1 & 7.3 & 0.59 & 0.71 & 0.74 & 0.77 & 3.1 & 4.0 & 4.1 & 4.2 \\
\hline & 19 & 2.8 & 4.5 & 5.7 & 5.9 & 0.49 & 0.55 & 0.57 & 0.59 & 2.7 & 3.6 & 3.7 & 3.9 \\
\hline & 22 & 2.7 & 4.2 & 5.5 & 5.7 & 0.47 & 0.52 & 0.55 & 0.58 & 2.6 & 3.8 & 3.9 & 3.6 \\
\hline & 25 & 2.5 & 4.1 & 5.3 & 5.6 & 0.45 & 0.54 & 0.56 & 0.54 & 2.5 & 3.7 & 4.0 & 3.5 \\
\hline \multirow{4}{*}{ Stem } & 5 & 1.1 & 1.9 & 2.1 & 2.3 & 0.11 & 0.20 & 0.23 & 0.24 & 0.8 & 1.7 & 1.5 & 1.4 \\
\hline & 19 & 1.2 & 1.4 & 1.9 & 2.0 & 0.08 & 0.09 & 0.12 & 0.14 & 0.4 & 0.9 & 1.1 & 1.3 \\
\hline & 22 & 1.0 & 1.3 & 1.6 & 1.8 & 0.07 & 0.08 & 0.10 & 0.09 & 0.5 & 0.8 & 1.0 & 1.1 \\
\hline & 25 & 0.9 & 1.2 & 1.4 & 1.3 & 0.04 & 0.06 & 0.08 & 0.07 & 0.4 & 0.7 & 0.9 & 0.8 \\
\hline \multirow{4}{*}{ Bark } & 5 & 2.8 & 4.6 & 4.5 & 4.7 & 0.21 & 0.32 & 0.34 & 0.35 & 4.7 & 3.6 & 3.3 & 3.1 \\
\hline & 19 & 2.4 & 1.9 & 3.5 & 3.3 & 0.10 & 0.15 & 0.16 & 0.18 & 4.5 & 1.9 & 1.8 & 1.7 \\
\hline & 22 & 2.3 & 3.6 & 3.4 & 3.1 & 0.09 & 0.11 & 0.13 & 0.15 & 4.1 & 1.7 & 1.6 & 1.5 \\
\hline & 25 & 2.2 & 3.4 & 3.2 & 2.9 & 0.07 & 0.09 & 0.11 & 0.14 & 3.8 & 1.5 & 1.3 & 1.4 \\
\hline \multirow{4}{*}{ Root } & 5 & 1.7 & 3.5 & 3.8 & 3.9 & 0.10 & 0.27 & 0.29 & 0.31 & 3.4 & 2.1 & 2.0 & 1.8 \\
\hline & 19 & 1.4 & 1.9 & 2.2 & 2.5 & 0.06 & 0.11 & 0.14 & 0.16 & 2.4 & 1.6 & 1.5 & 1.4 \\
\hline & 22 & 1.6 & 1.7 & 2.1 & 2.4 & 0.05 & 0.12 & 0.12 & 0.17 & 2.1 & 1.7 & 1.6 & 1.5 \\
\hline & 25 & 1.2 & 1.5 & 2.0 & 2.2 & 0.08 & 0.10 & 0.14 & 0.15 & 2.0 & 1.4 & 1.3 & 1.2 \\
\hline
\end{tabular}

TABle 3: The biomass range $(w)$ of a single Chinese fir and the percentage of its organs.

\begin{tabular}{|c|c|c|c|c|c|c|c|c|c|}
\hline \multirow{2}{*}{$\begin{array}{l}\text { Stand } \\
\text { age }(t / a)\end{array}$} & \multirow[b]{2}{*}{ Organ } & \multicolumn{2}{|c|}{ Site index $S=5$} & \multicolumn{2}{|c|}{ Site index $S=18$} & \multicolumn{2}{|c|}{ Site index $S=21$} & \multicolumn{2}{|c|}{ Site index $S=23$} \\
\hline & & W (kg) & $\begin{array}{c}\text { Percentage } \\
(\%)\end{array}$ & W (kg) & $\begin{array}{c}\text { Percentage } \\
(\%)\end{array}$ & W (kg) & $\begin{array}{c}\text { Percentage } \\
(\%)\end{array}$ & W (kg) & $\begin{array}{c}\text { Percentage } \\
(\%)\end{array}$ \\
\hline \multirow{6}{*}{$5 a$} & Leaf & $1.67 \pm 0.58$ & 21.44 & $3.48 \pm 0.95$ & 24.34 & $3.98 \pm 1.04$ & 22.04 & $4.12 \pm 1.39$ & 18.7 \\
\hline & Branch & $1.25 \pm 0.44$ & 16.05 & $2.36 \pm 0.84$ & 16.50 & $2.78 \pm 1.21$ & 15.4 & $3.47 \pm 1.32$ & 15.7 \\
\hline & Stem & $2.60 \pm 0.8$ & 33.40 & $4.40 \pm 1.08$ & 30.77 & $5.64 \pm 1.94$ & 31.23 & $6.37 \pm 2.51$ & 33 \\
\hline & Bark & $0.53 \pm 0.12$ & 6.804 & $0.96 \pm 0.33$ & 6.71 & $1.46 \pm 0.68$ & 8.08 & $1.98 \pm 0.83$ & 9 \\
\hline & Root & $1.74 \pm 0.66$ & 22.33 & $3.10 \pm 0.92$ & 21.68 & $4.20 \pm 1.46$ & 23.25 & $5.24 \pm 2.07$ & 23.6 \\
\hline & Tree & $7.79 \pm 2.6$ & 100.00 & $14.30 \pm 4.12$ & 100.00 & $18.06 \pm 6.33$ & 100.00 & $22.04 \pm 8.12$ & 100.00 \\
\hline \multirow{6}{*}{$19 \mathrm{a}$} & Leaf & $2.64 \pm 0.92$ & 4.11 & $5.27 \pm 1.47$ & 5.04 & $5.98 \pm 2.09$ & 5.14 & $6.34 \pm 2.87$ & 4.83 \\
\hline & Branch & $4.43 \pm 2.05$ & 6.90 & $7.61 \pm 2.44$ & 7.28 & $8.22 \pm 3.08$ & 7.06 & $9.12 \pm 4.43$ & 7.00 \\
\hline & Stem & $40.36 \pm 15.7$ & 63.00 & $64.13 \pm 20.6$ & 61.34 & $72.33 \pm 24.3$ & 62.12 & $81.2 \pm 29.7$ & 62 \\
\hline & Bark & $6.78 \pm 2.11$ & 10.60 & $11.30 \pm 4.87$ & 10.84 & $13.11 \pm 5.11$ & 11.3 & $15.10 \pm 7.05$ & 12 \\
\hline & Root & $9.97 \pm 3.01$ & 16 & $16.20 \pm 5.56$ & 15.50 & $16.80 \pm 6.76$ & 14.38 & $19.40 \pm 8.11$ & 14.8 \\
\hline & Tree & $64.18 \pm 23.79$ & 100.00 & $104.51 \pm 34.94$ & 100.00 & $116.44 \pm 41.34$ & 100.00 & $131.16 \pm 44.86$ & 100.00 \\
\hline \multirow{6}{*}{$22 \mathrm{a}$} & Leaf & $4.22 \pm 1.27$ & 4.66 & $6.37 \pm 2.02$ & 4.89 & $6.89 \pm 2.94$ & 4.76 & $7.26 \pm 3.16$ & 4.53 \\
\hline & Branch & $5.11 \pm 2.31$ & 5.64 & $8.78 \pm 3.11$ & 6.74 & $9.89 \pm 3.84$ & 6.84 & $10.43 \pm 4.38$ & 6.50 \\
\hline & Stem & $56.7 \pm 20.4$ & 62.6 & $77.32 \pm 26.21$ & 59.36 & $87.34 \pm 32.30$ & 60.45 & $98.53 \pm 41.1$ & 61.4 \\
\hline & Bark & $9.12 \pm 4.1$ & 10.1 & $14.40 \pm 5.98$ & 11.1 & $15.21 \pm 6.12$ & 10.53 & $16.32 \pm 7.14$ & 10.2 \\
\hline & Root & $15.5 \pm 6.52$ & 17.1 & $23.40 \pm 9.70$ & 17.91 & $25.16 \pm 11.6$ & 17.41 & $27.89 \pm 13.1$ & 17.4 \\
\hline & Tree & $90.65 \pm 34.6$ & 100.00 & $130.27 \pm 47.02$ & 100.00 & $144.49 \pm 56.8$ & 100.00 & $160.43 \pm 68.8$ & 100.00 \\
\hline \multirow{6}{*}{$25 a$} & Leaf & $5.64 \pm 1.62$ & 5.3 & $8.65 \pm 2.61$ & 5.70 & $9.16 \pm 3.16$ & 5.60 & $10.38 \pm 4.21$ & 5.73 \\
\hline & Branch & $6.10 \pm 2.65$ & 5.7 & $9.76 \pm 3.46$ & 6.43 & $10.78 \pm 3.91$ & 6.60 & $11.70 \pm 4.61$ & 6.50 \\
\hline & Stem & $63.2 \pm 24.7$ & 60 & $88.70 \pm 28.70$ & 58.5 & $96.80 \pm 31.3$ & 59.10 & $108.3 \pm 35.9$ & 59.8 \\
\hline & Bark & $11.7 \pm 5.22$ & 11 & $15.90 \pm 6.21$ & 10.5 & $16.80 \pm 7.41$ & 10.26 & $17.70 \pm 8.01$ & 9.8 \\
\hline & Root & $20.4 \pm 7.59$ & 19.1 & $28.70 \pm 9.53$ & 18.87 & $30.24 \pm 11.2$ & 18.5 & $33.12 \pm 13.41$ & 18.3 \\
\hline & Tree & $107.04 \pm 41.78$ & 100.00 & $151.71 \pm 50.51$ & 100.00 & $163.78 \pm 56.98$ & 100.00 & $181.2 \pm 66.14$ & 100.00 \\
\hline
\end{tabular}

per unit area of Chinese fir forest and the average nutrient content $C$ is $X=n w C / 1000=\mathrm{CW}$, where, $n$ is the stand density, $w$ is the average biomass per tree (kg/plant), and $\mathrm{W}$ is the biomass per unit area $\left(t / \mathrm{hm}^{2}\right)$.
2.3. Analysis of Influencing Factors. There are a series of important indexes to calculate the amount of fertilizer applied to trees, such as site index, forest age, nutrient concentration of dominant trees, dominant wood biomass, average wood 
biomass, fertilizer utilization rate, and target yield. The site index is a natural environmental factor required for forest production and is a collection of conditions such as moisture, temperature, light intensity, and soil fertility. In the forest area with high site index or low site index, the fertilization effect is difficult to show. In the forest area with high site index, the soil fertility, water, temperature, light, and other conditions are very good. After fertilization, the effect on the increase of forest yield is small. On the contrary, the soil fertility, water, temperature, light, and other conditions are very poor in the forest land with low site index. After fertilization, due to natural factors, the fertilization effect is also very poor. In the effective site index interval, the theoretical limit value of forest production is the dominant wood biomass of forest land in practice, so the dominant wood nutrient content is the limit value that can be reached by the average wood nutrient content after fertilization. If the difference between the dominant wood biomass and the average wood biomass is greater, the fertilization effect will be better. In addition, the target yield is also related to the amount of fertilization. The target yield is determined by the input-output ratio of forest land in previous years, and the target yield determines the target increase yield, that is, the amount of fertilization. The relative intensities of the absorbed nutrients of different forest ages are different. The best fertilization period, the more fertilizer is absorbed. At the same time, the utilization rate of the fertilizer is related to the physical and chemical properties of the soil. The physical and chemical properties of the soil in different forest land are different, so the utilization rate of the fertilizer is also different. The higher the utilization rate, the better the fertilizer effect. Generally, three kinds of fixed nitrogen, phosphorus, and potassium fertilizers are applied in forest land. The utilization rate of fertilizer is observed according to the different physical and chemical properties of soil in different forest land. Therefore, seven factors including site index, forest age, nutrient concentration of dominant trees, dominant wood biomass, average wood biomass, fertilizer utilization rate, and target yield were selected as the influencing factors of forest fertilizer application.

2.4. Data Normalization. Three hundred tree growth and nutrient measurement records were obtained. The data of each group were $X_{1}$ site index, $X_{2}$ forest age, $X_{3}$ dominant wood-related nutrient concentration, $X_{4}$ dominant wood biomass, $X_{5}$ average wood biomass, $X_{6}$ target production, and $X_{7}$ fixed fertilizer utilization rate. Since the input parameters have different dimensions and the orders of magnitude of units are also greatly different, these will have a great impact on the training of neural network. Therefore, the input parameters need to be normalized. In order to improve the training efficiency, an accurate fertilization model is established. The minimum maximum transformation method is used to normalize different data and deal with the dimensional influence between data. The parameters are in the range of $[-1,1]$, and then the parameters of neural network are trained. The following formula is adopted for normalization:

$$
y=\frac{x-x_{\min }}{x_{\max }-x_{\min }}
$$

Map the data to $(-1,+1)$ and replace the formula with

$$
y=y * 2-1 \text {, }
$$

where $y$ is the normalized value, $x$ is the original value of a parameter, $x_{\max }$ is the maximum value in the set of values, and $x_{\min }$ is the minimum value in the set of values.

2.5. Basic BPNN Model. The structure of the basic BPNN consists of the input layer, the hidden layer, and the output layer, as shown in Figure 1. The BPNN algorithm consists of two parts: the forward transfer of the input data and the back propagation of the error between the output data and the expected data $[26,27]$. One part is the input data through the input layer to the hidden layer, the hidden layer to the output layer. In the process, the calculation will be based on the given initial weight and threshold, and finally the output data will be obtained. The other part is to calculate the error change value $\delta j(k)$ between the actual output and the expected value and then turn to the back propagation, and the error signal $\delta j(k)$ is propagated back through the original connection path through the network to modify the weight of each layer of neurons. The value $\omega i j(j k)$ and the threshold $\theta j(k)$ until the target accuracy are reached.

The hidden layer of BPNN can be one or more layers. It is proved theoretically that the neural network of a single hidden layer can approximate the nonlinear function with arbitrary precision, so that the model can realize the nonlinear mapping from input to output. With the increase of the number of hidden layers, the output error of the network will decrease [28]. Therefore, the increase of hidden layers will improve the accuracy of the network but will make the network structure become complex, the running time become longer, and even lead to the overfitting phenomenon. Therefore, after the number of neurons in the hidden layer is determined by empirical formula, the structure of BPNN tree fertilization model is 3-layer structure of 7-12-1.

The BPNN has strong nonlinear mapping ability, selfadaptive and good self-learning ability, and strong fault tolerance. In the absence of a mathematical model, the nonlinear mapping between the amount of fertilizer applied to trees and the factors affecting the effect of fertilization can be realized. By learning and training the relationship between input and output data, when the actual output value and the expected value have a large error, the weights and thresholds of each layer of the neural network are constantly updated until the accuracy of network error is reached, so as to better improve the model.

In the figure, $i, j$, and $k$ are the number of neurons in each layer; $x_{i}$ is any input signal of each group of data in the input $p$ in the input layer; $\omega_{i j}, \omega_{j k}$ and $\theta_{j}, \theta_{k}$, respectively, represent the weight and threshold of each layer; $\varphi(\cdot)$ and $\tau(\cdot)$ represent the hidden layer and output layer activation functions, respectively. In the BP neural network algorithm, the hidden layer neurons input the signal net ${ }_{j}$ when the sample $p$ acts. 


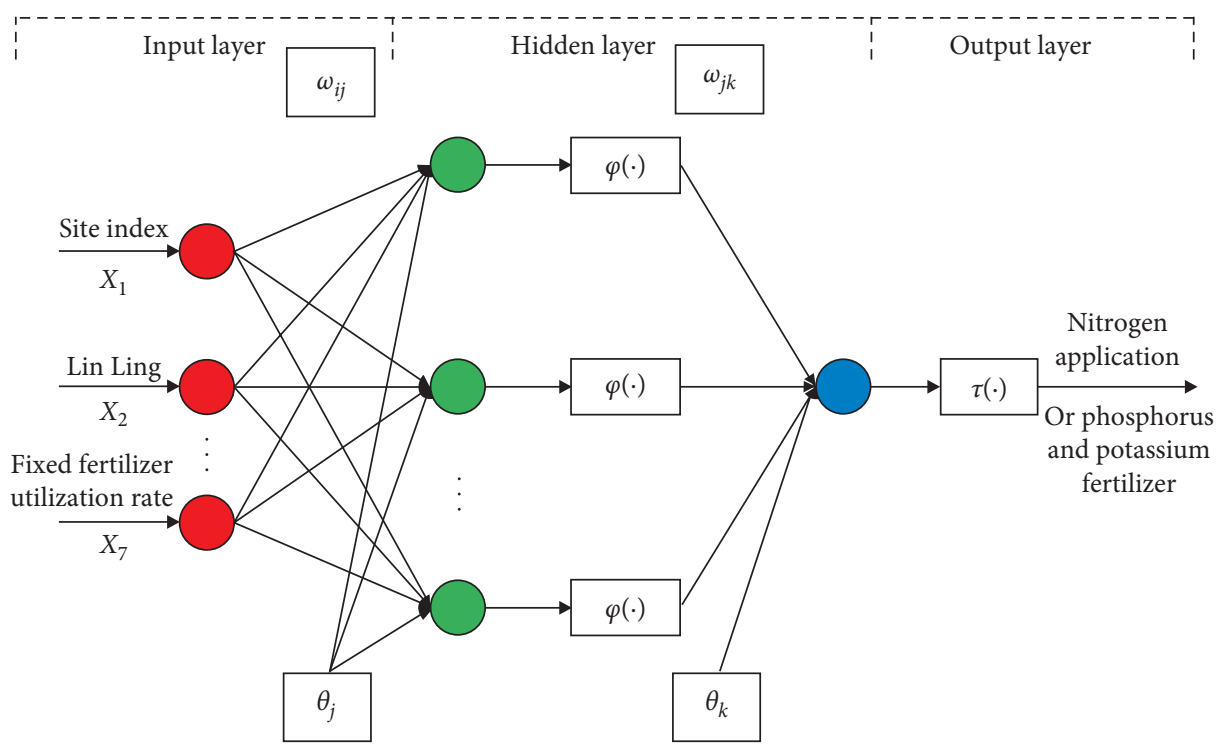

FIgURE 1: BP neural network structure.

$$
\operatorname{net}_{j}=\sum \omega_{i j} x_{i}+\theta_{j}
$$

The hidden layer neuron node outputs a signal $o_{j}$ when the sample $p$ acts:

$$
o_{j}=\varphi\left(\text { net }_{j}\right)=\varphi\left(\sum \omega_{i j} x_{i}+\theta_{j}\right)
$$

The output layer neuron node inputs the signal net $k$ when the sample $p$ acts:

$$
\begin{aligned}
\operatorname{net}_{k} & =\sum \omega_{j k} O_{j}+\theta_{k} \\
& =\sum\left(\omega_{j k} \varphi\left(\sum \omega_{i j} x_{i}+\theta_{j}\right)+\theta_{k}\right) .
\end{aligned}
$$

The output layer neurons output the signal $y_{k}$ when the sample $p$ acts:

$$
\begin{aligned}
y_{k} & =\tau\left(\text { net }_{k}\right) \\
& =\tau\left(\sum\left(\omega_{j k} \varphi\left(\sum \omega_{j} x_{i}+\theta_{j}\right)+\theta_{k}\right)\right) .
\end{aligned}
$$

In the formula, $\eta$ is the error back propagation learning rate $(0<\eta<1), \delta_{j(k)}$ is the error signal of each layer, and the weight and threshold are updated and iterated according to

$$
\begin{aligned}
\Delta \omega_{i j(j k)} & =\eta \delta_{j(k)} O_{i(j)}, \\
\Delta \theta_{j(k)} & =\eta \delta_{j(k)} .
\end{aligned}
$$

The error variation value of each layer gradually corrects the fertilization model during the back propagation process.

2.6. Particle Swarm Optimization BPNN Model. When a single BPNN model is used to predict the precise fertilization amount of forest trees, the error between the actual output and the expected value is still large, because in the actual use, the convergence speed of the network is relatively slow, and it is easy to fall into the local optimization, even when there are few training samples, and there may be a fitting problem. Particle swarm optimization algorithm has better global optimization ability. Therefore, the particle swarm optimization algorithm was proposed to optimize the BPNN model. The particle swarm optimization (PSO) algorithm is a swarm intelligence optimization algorithm [29, 30]. The velocity characteristics, fitness value, and position were used to represent the motion characteristics of the particle. After initializing the potential optimal solution particles, the speed of the particles determines the search direction and distance of the particles, the fitness value determines the quality of the particles. When the particles move in the preset space, the position is changed according to the individual optimal solution and the global optimal solution. By updating the fitness value of the particle, the fitness value is the smallest. The position corresponding to the particle is the optimal solution, as shown in Figure 2, the motion of particles in the particle swarm leaving its current position in the search area, the velocity $v_{i+1}$ that this particle is about to update is a combination of various factors, It includes $v_{i}, v_{p}$, and $v_{G}$, which are the current particle speed, the past best experience of individual particles, and the best experience of population particles.

The weights and thresholds of each layer in the BPNN can be represented by individual particle swarms. The individual swarms are coded, represented by the position vector of the particle swarm, and the optimal population particles are output by the iterative algorithm. After decoding, the BPNN global optimal is obtained. Weight and threshold establish a PSO-BPNN algorithm model. After decoding, the global optimal weight and threshold of BPNN are obtained, and the pso-bpnn algorithm model with 3layer structure of 7-12-1 is established.

2.7. GRA-PSO-BPNN Model Construction Process. The degree of correlation can delicate the correlation in mutual matters and factors, and the Grey correlation degree analysis method can express the changeable situation in mutual matters and factors. Taking the timeliness and regionality of 


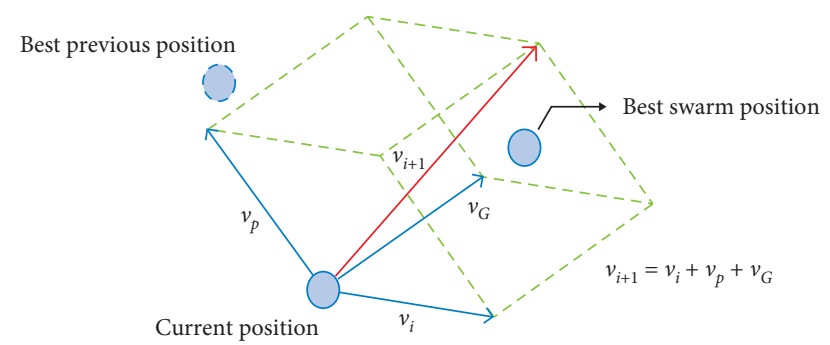

Figure 2: Particle movement in a swarm.

the fertilization model into consideration, different forests have different factors that affect the accuracy of fertilization, resulting that there is no certain model to implement the fertilization model to achieve the accurate prediction so that the accurate rate of the prediction is not so well. This research adopts the analysis method of Grey Relational degree which can analyze the key factors that influence the fertilizer application amount in different areas and on the basis of the annual forest data updated by artificial forest, which can make the accurate fertilization come true. The grey relation analysis method is used to calculate the grey relation between input variables and output results. The specific steps are as follows:

Step 1: Using the formula (9), establish a data matrix $x_{i}$

$$
x_{i}=\left(x_{i}(1), x_{i}(2), x_{i}(3), \ldots, x_{i}(300)\right),
$$

where $X_{i}$ (1), $X_{i}$ (2), $X_{i}(3), \ldots, X_{i}$ (300) represents the number of sequences. Among them, $i$ represents site index, forest age, nutrient concentration related to dominant wood, biomass of dominant wood, average biomass of wood, fixed fertilizer utilization rate, and target yield, which are different factors affecting the fertilization effect.

Step 2: Establish an initialization change matrix $x_{i}^{\prime}$ using

$$
\begin{aligned}
x_{i}^{\prime} & =\left(\frac{x_{i}(1)}{x_{i}(1)}, \frac{x_{i}(2)}{x_{i}(1)}, \frac{x_{i}(3)}{x_{i}(1)}, \ldots, \frac{x_{i}(300)}{x_{i}(1)}\right) \\
& =\left(x_{i}^{\prime}(1), x_{i}^{\prime}(2), x_{i}^{\prime}(3), \ldots, x_{i}^{\prime}(300)\right) .
\end{aligned}
$$

Step 3: Use formula (11) to calculate the difference sequence, where $k$ represents the sequence number:

$$
\Delta_{o i}(k)=\operatorname{abs}\left(x^{i}(k)-x_{i}^{\prime}\right)=\left(\Delta_{o i}(1), \Delta_{o i}(2), \ldots, \Delta_{o i}(300)\right) .
$$

Step 4: Calculate the correlation coefficient and the grey correlation degree by using equations (12) and (13).

Step 4: Use formulas (12) and (13) to calculate correlation coefficient and grey correlation degree. $\varphi$ is the resolution coefficient, $0<\varphi<1$. In this study, $\varphi=0.5$ :

$$
\begin{aligned}
\xi_{o i}(k) & =\frac{\min _{i} \min _{k} \Delta_{o i}(k)+\varphi \max _{i} \max _{k} \Delta_{o i}(k)}{\Delta_{o i}(k)+\varphi \min _{i} \min _{k} \Delta_{o i}(k)}, \\
\gamma_{o i} & =\frac{1}{300} \sum_{1}^{300} \xi_{o i}(k) .
\end{aligned}
$$

According to the calculation formula of grey correlation coefficient, the minimum difference $\min _{i} \min _{k} \Delta_{o i}(k)$ and the maximum difference $\max _{i} \max _{k} \Delta_{o i}(k)$ of $N, P$, and $K$ fertilizers were $8.822 e-06,3.483 ; 7.1719 e-05,7.307$; $2.388 e-04,1.201$, respectively; Table 4 shows the grey correlation coefficient and grey correlation degree between the input variables and the output of the prediction model of forest precise fertilization of nitrogen, phosphorus, and potassium.

According to the above analysis, the grey correlation degree of $X_{1}$ site index, $X_{2}$ forest age, $X_{3}$ dominant woodrelated nutrient concentration, $X_{4}$ dominant wood biomass, $X_{5}$ average wood biomass, and $X_{6}$ target yield is higher, and $X_{7}$ fixed fertilizer utilization rate is smaller; this study uses data reduction, grey correlation analysis, to reduce the influencing factors of different forest areas for predicting and calculating forest fertilization, identifying key factors affecting forest fertilization and providing more effective input for the prediction model.

Step 1 defines the input and output of the GRA-PSOBPNN model.

Compared with the PSO-BPNN model, using the grey correlation analysis, the site index, the forest age, the dominant wood-related nutrient content, the dominant wood biomass, the average wood biomass, and the target yield are used as the network input, and the actual fertilization amount is used as the output. Therefore, there are 300 records, 200 for training and 100 for validation. In the formula, the number of neurons in the input layer $x$ is 6 , and the number of neurons in the output layer $y$ is 1 . The empirical formula is used to determine the number $m$ of hidden neurons:

$$
m=\sqrt{x+y}+a, \quad a \in[1,10] .
$$

The reduction of network error can not only adjust the number of hidden layer neurons, but also increase the number of hidden layer. However, increasing the number of hidden layers will complicate the network, increase the training time, and even overfitting. It is biased towards selecting the single hidden layer BPNN [31]. As mentioned above, the structure of GRA-PSOBPNN model is determined to be a 3-layer structure of 6-12-1.

Step 2: Particle Swarm Initialization.

The weights and thresholds in the BPNN model are the parameters to be optimized by the PSO algorithm. At the beginning, a certain number of particle swarm individuals can be randomly generated to represent, 
TABLE 4: Grey correlation degree and grey correlation coefficient of each influencing factor and output fertilization amount.

\begin{tabular}{|c|c|c|c|c|c|c|c|c|}
\hline$X_{N i}$ & $\varepsilon_{o i}$ & $r_{o i}$ & $X_{P i}$ & $\varepsilon_{o i}$ & $r_{o i}$ & $X_{K i}$ & $\varepsilon_{o i}$ & $r_{o i}$ \\
\hline$X_{1}$ & $\varepsilon_{o 1}=(0.9178, \ldots, 0.8813)$ & 0.9105 & $X_{1}$ & $\varepsilon_{o 1}=(0.9512, \ldots, 0.8731)$ & 0.9334 & $X_{1}$ & $\varepsilon_{o 1}=(0.7483, \ldots, 0.4639)$ & 0.7512 \\
\hline$X_{2}$ & $\varepsilon_{o 2}=(0.9259, \ldots, 0.8947)$ & 0.9122 & $X_{2}$ & $\varepsilon_{o 2}=(0.9554, \ldots, 0.8793)$ & 0.9357 & $X_{2}$ & $\varepsilon_{o 2}=(0.7644, \ldots, 0.4744)$ & 0.7559 \\
\hline$X_{3}$ & $\varepsilon_{o 3}=(0.8972, \ldots, 0.9323)$ & 0.9115 & $X_{3}$ & $\varepsilon_{o 3}=(0.9372, \ldots, 0.9191)$ & 0.9441 & $X_{3}$ & $\varepsilon_{o 3}=(0.7312, \ldots, 0.6561)$ & 0.7606 \\
\hline$X_{4}$ & $\varepsilon_{o 4=}(0.9240, \ldots, 0.9390)$ & 0.9232 & $X_{4}$ & $\varepsilon_{o 4=}(0.9544, \ldots, 0.8992)$ & 0.9398 & $X_{4}$ & $\varepsilon_{o 4=}(0.7605, \ldots, 0.5119)$ & 0.7715 \\
\hline$X_{5}$ & $\varepsilon_{o 5=}(0.9338, \ldots, 0.9554)$ & 0.9009 & $X_{5}$ & $\varepsilon_{o 5=}(0.9594, \ldots, 0.9063)$ & 0.9321 & $X_{5}$ & $\varepsilon_{o 5}=(0.7800, \ldots, 0.5262)$ & 0.7372 \\
\hline$X_{6}$ & $\varepsilon_{o 6}=(0.9194, \ldots, 0.9516)$ & 0.9119 & $X_{6}$ & $\varepsilon_{o 6=}(0.9520, \ldots, 0.9046)$ & 0.9368 & $X_{6}$ & $\varepsilon_{o 6=}(0.7514, \ldots, 0.5229)$ & 0.7561 \\
\hline$X_{7}$ & $\varepsilon_{o 7=}(0.6660, \ldots, 0.6646)$ & 0.6142 & $X_{7}$ & $\varepsilon_{o 7=}(0.6016, \ldots, 0.6144)$ & 0.6736 & $X_{7}$ & $\varepsilon_{o 7}=(0.3952, \ldots, 0.3762)$ & 0.5868 \\
\hline
\end{tabular}

and the global optimal position gbest and the individual optimal position pbest of the particle are initialized. The sum of ownership value and threshold value in network structure is the dimension $d$ of particle swarm individual search space, that is,

$$
d=x m+m y+m+y \text {. }
$$

The $d$-dimensional vector $x_{i}^{t}=\left(x_{i 1}^{t}, x_{i 2}^{t}, \ldots, x_{i d}^{t}\right)$ represents the position vector of the $i^{t \mathrm{th}}$ particle in the $t^{\text {th }}$ generation population.

Step 3: Particle Velocity Location Update.

According to the following formula, the particle velocity is updated according to the individual optimal solution and the global optimal solution.

$$
\begin{aligned}
& v(t+1)=w \cdot v(t)+c_{1} \cdot r_{1} \cdot((\operatorname{pbest}(t)-x(t)) \\
& \left.\quad+c_{2} \cdot r_{2} \cdot(\operatorname{gbest}(t)-x(t))\right) .
\end{aligned}
$$

Among them, pbest $(t)$ and gbest $(t)$ are the individual optimal solution of the $i^{\text {th }}$ particle in the $t^{\text {th }}$ generation of the $d$-dimensional space, and the global optimal solution in the $t^{\text {th }}$ generation, $r_{1}$ and $r_{2}$ are in $[0,1], c_{1}, c_{2}$ are learning factors, $w$ is the inertia weight, and the particle position is updated according to the following formula:

$$
x(t+1)=x(t)+v(t+1) .
$$

The particle group can be evaluated by calculating the fitness value. The smaller the fitness value of the particle group is, the higher the fitness is. The speed and position of each particle are adjusted based on the fitness value. The particle fitness is calculated according to the following formula. Value $F$ is

$$
F=\sum_{i=1}^{N} \mathrm{abs}\left(y_{i}-t_{i}\right),
$$

where $N$ is the number of samples in the test area; abs is the absolute value function; $y_{i}$ is the actual value of the sample $i$; and $t_{i}$ is the predicted value of the sample $i$. Step 4: Optimal Population Particles:

When the number of population evolution reaches the upper limit $T$ or the iteration error reaches the set precision $e$, when the algorithm stops, the global optimal solution can be obtained and mapped to the weight and threshold of the BP network.

\section{Step 5: GRA-PSO-BPNN Model Training.}

After determining the GRA-PSO-BPNN weights and thresholds, the training data are input to train the GRAPSO-BPNN model. The entire model flow is shown in Figure 3.

\section{Case Study}

300 groups of tree growth and nutrient dynamic test data were measured in the test area, and the test data were divided into two parts. Among them, 200 groups of experimental data were used as training data to train the stage accurate fertilization model of forest based on neural network, and 100 groups of experimental data were used as the verification set of test fertilization model.

BPNN models optimized by different algorithms are compared and verified in the experiment. Tansig function and purelin function are, respectively, assigned as the activation functions of hidden layer and output layer. In the process of adjusting parameters of BPNN model, the accuracy is found higher when the maximum training times of BPNN model reaches about 200 times, while big error and inconsistencies occur when the training times are more than or less than 200 times. Therefore, the max of training times of the model is set to 200, the target error is 0.00001 , and the learning rate is 0.1. Even so, the target accuracy is still unachievable, and the training time is about $5 \sim 8 \mathrm{~s}$. Based on the BPNN model, the PSO algorithm was used for optimization. When adjusting the parameters of the PSO-BPNN model, it is found that accuracy was higher when the population size was about 200 and the training time was about $8 \sim 14 \mathrm{~s}$. When the population size is significantly lower than 200, the accuracy becomes lower; when the population size is significantly higher than 200, the accuracy remains the same, but the training time becomes longer. At the same time, the accuracy is higher when the max of training times of the PSO-BPNN model is in the range of about 200 times; the accuracy however becomes lower when it is significantly lower than 200 times. When the training times greatly exceed 200, the accuracy remains the same and the training time becomes longer. Therefore, the maximum training times of the model is set as 200 . The population size of the particles in the PSO algorithm is 200, the inertia weight is 1 , and the learning factor $c_{1}=c_{2}=1.5$. The parameters remain unchanged and the training time is about $4 \sim 10 \mathrm{~s}$ when the PSO-BP model is improved to GRA-PSO-BPNN model for training. With regard to the basic BPNN, PSO-BPNN, and GRA-PSO-BPNN training models, Figures 4-6 show the 


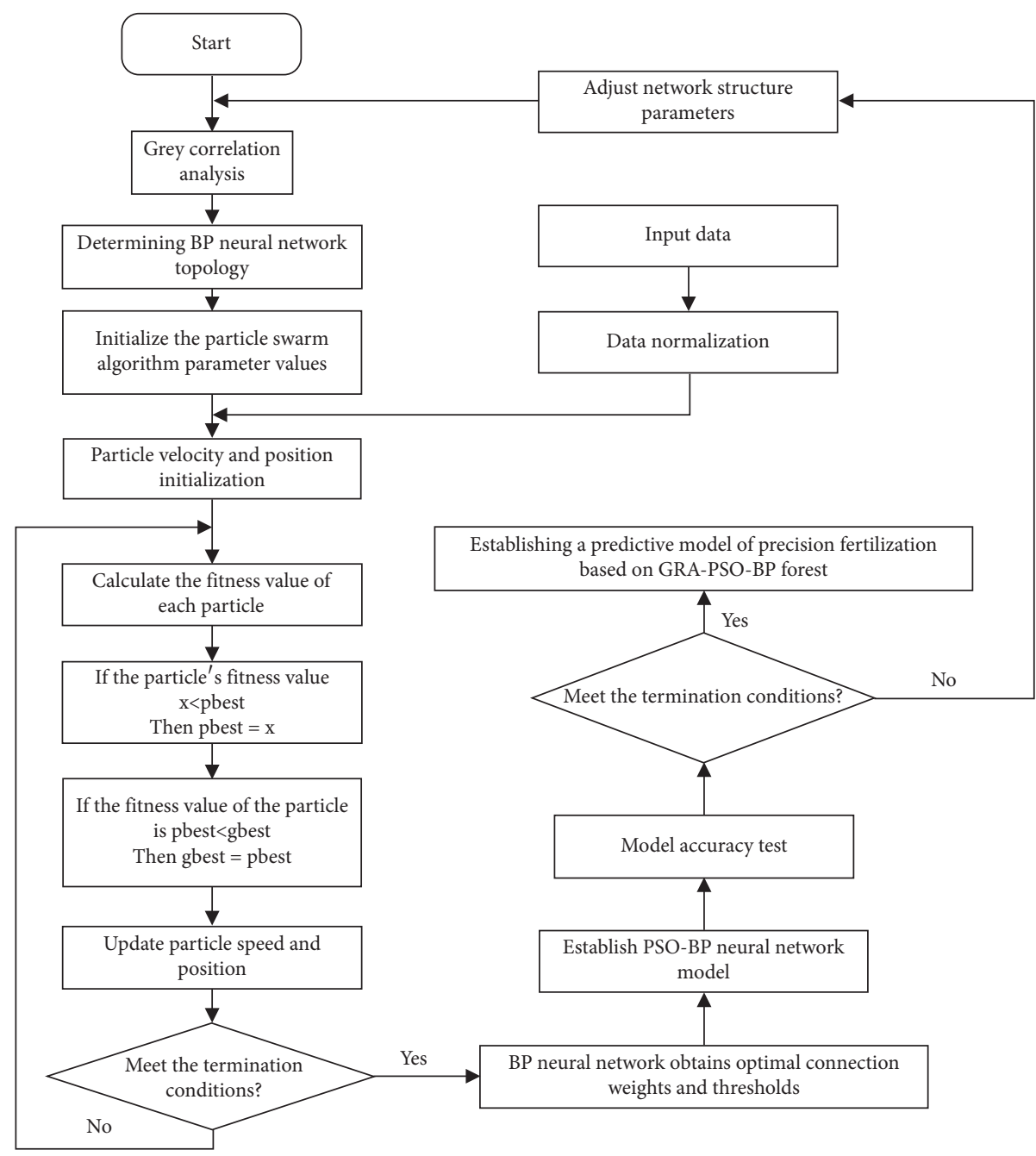

FIGURE 3: GRA-PSO-BPNN model flow chart.

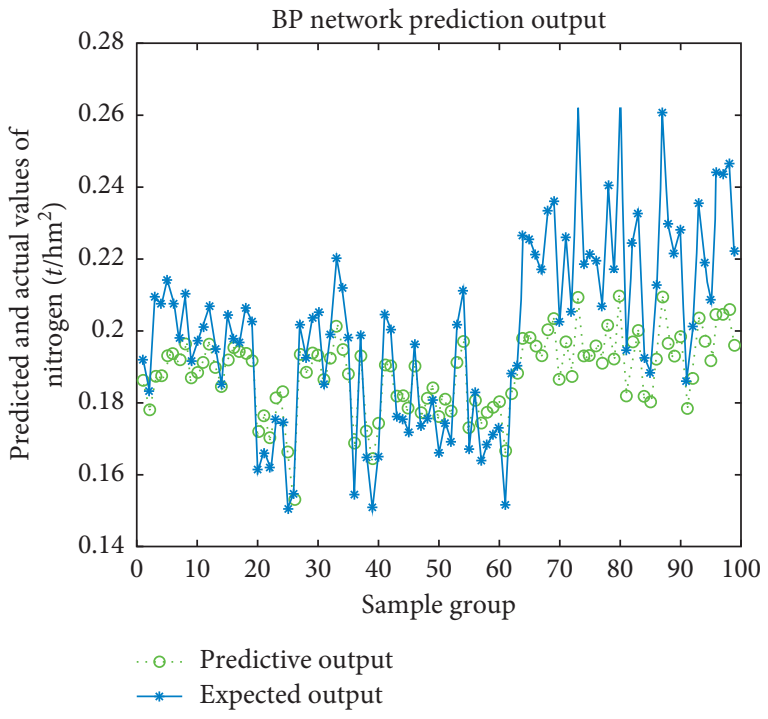

(a)

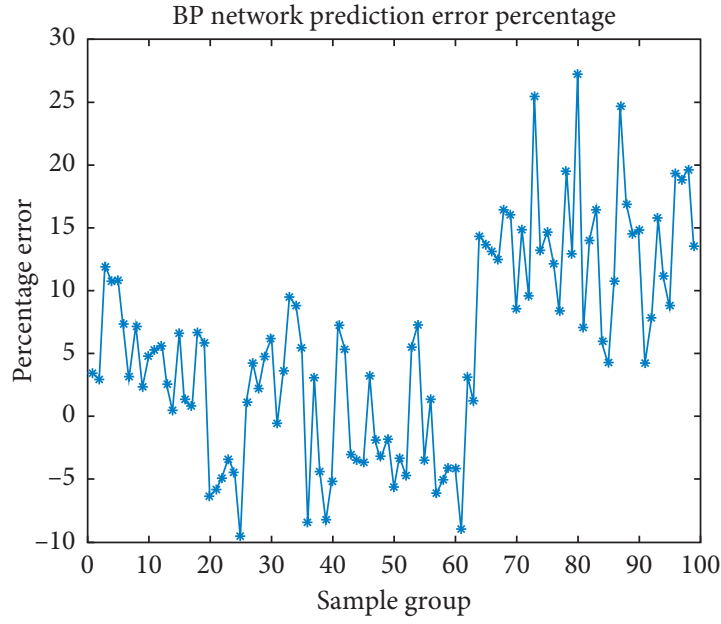

(b)

FIgUre 4: Continued. 

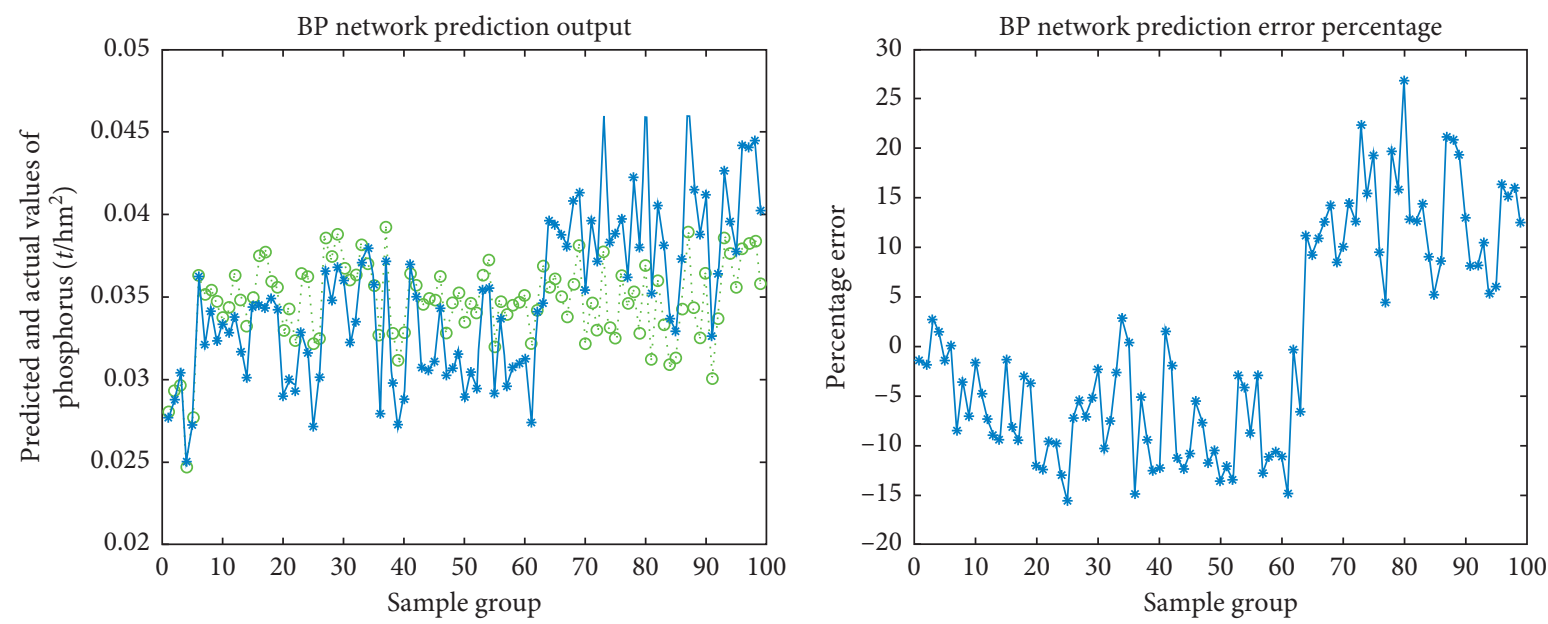

o. Predictive output

$\rightarrow$ Expected output

(c)

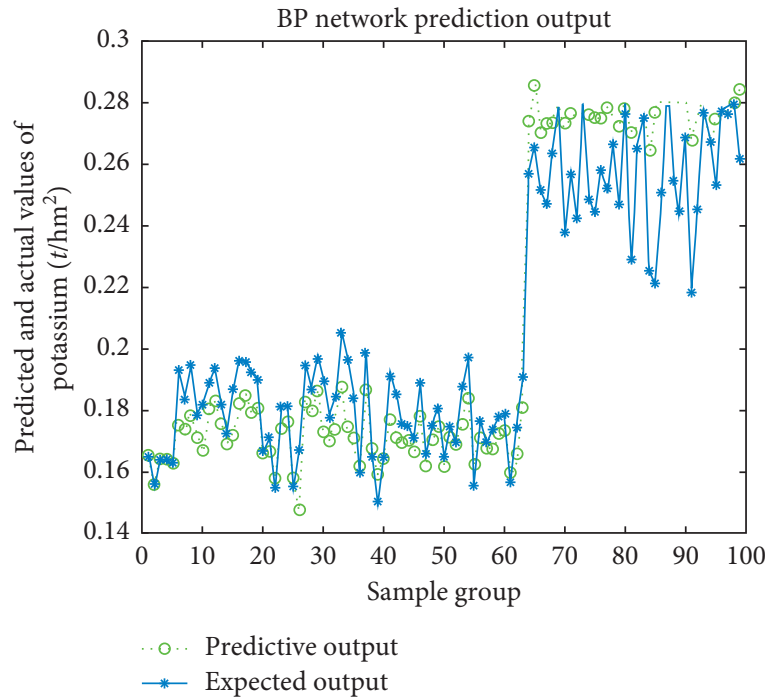

(d)

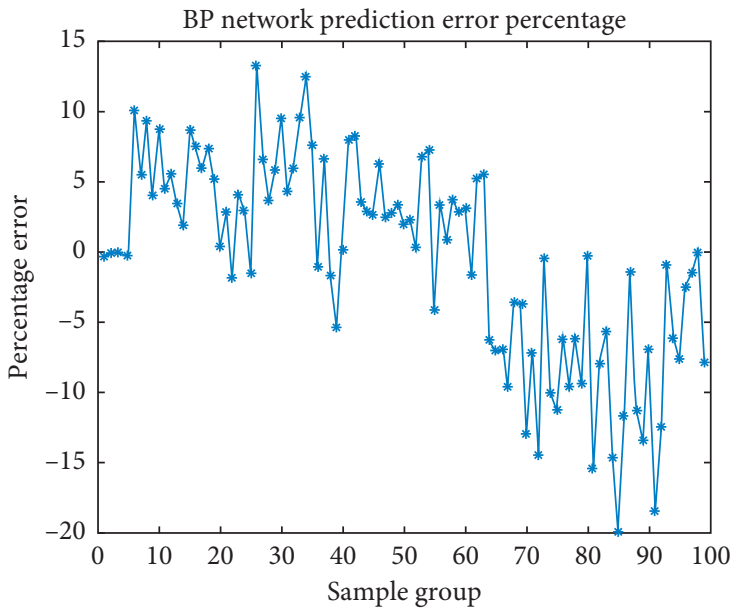

(e)

(f)

FIGURE 4: Prediction results and error analysis of nitrogen, phosphorus, and potassium fertilizer application rates in BP model.

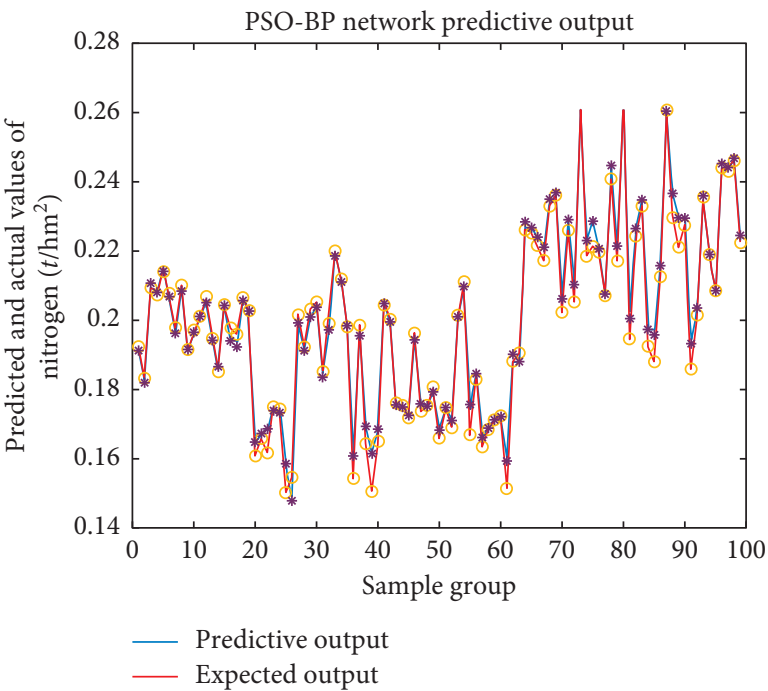

(a)

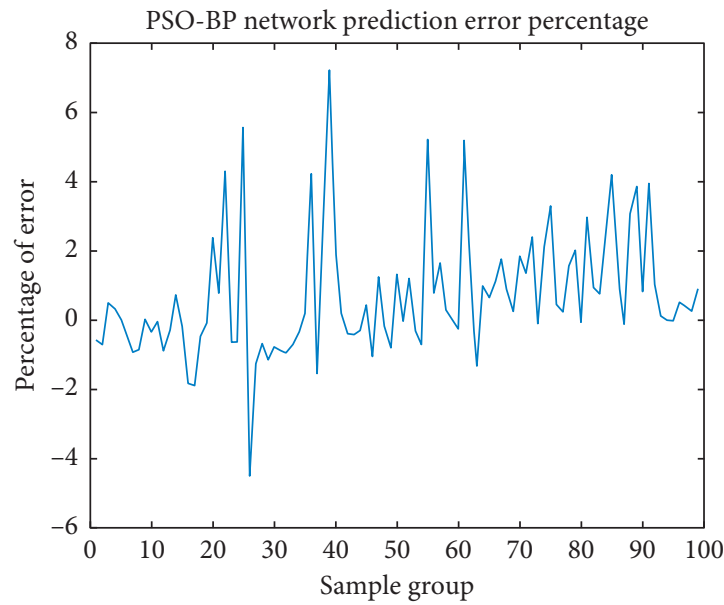

(b)

Figure 5: Continued. 


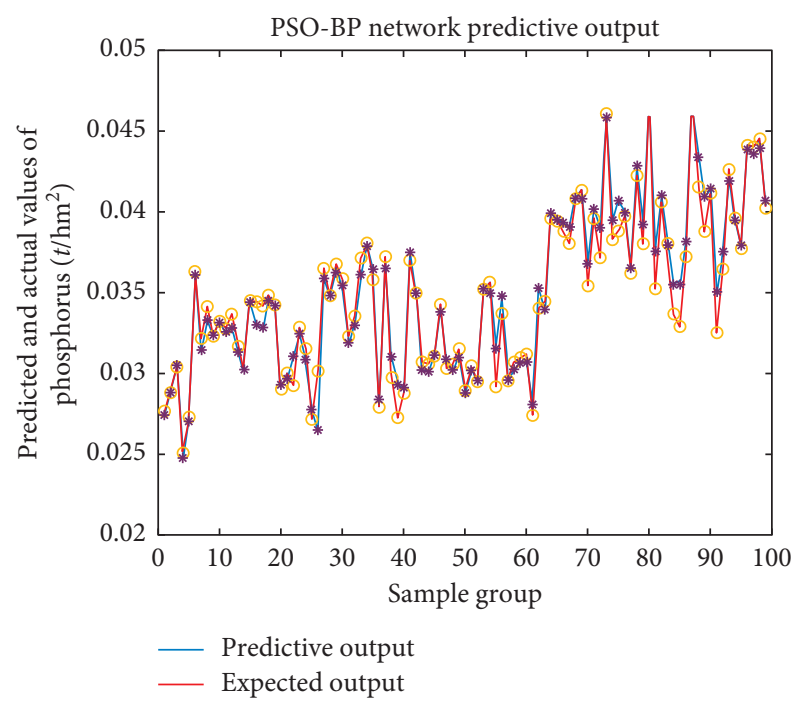

(c)

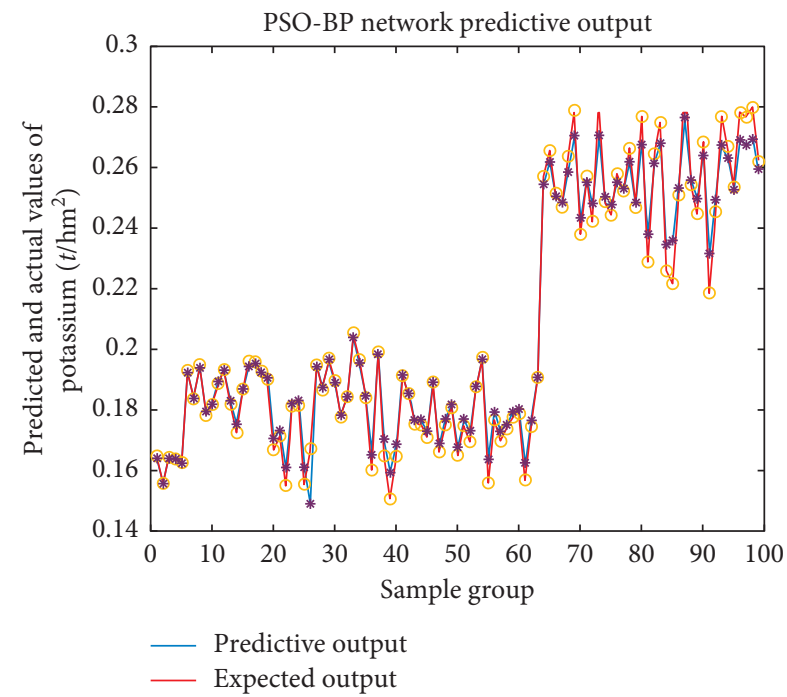

(e)

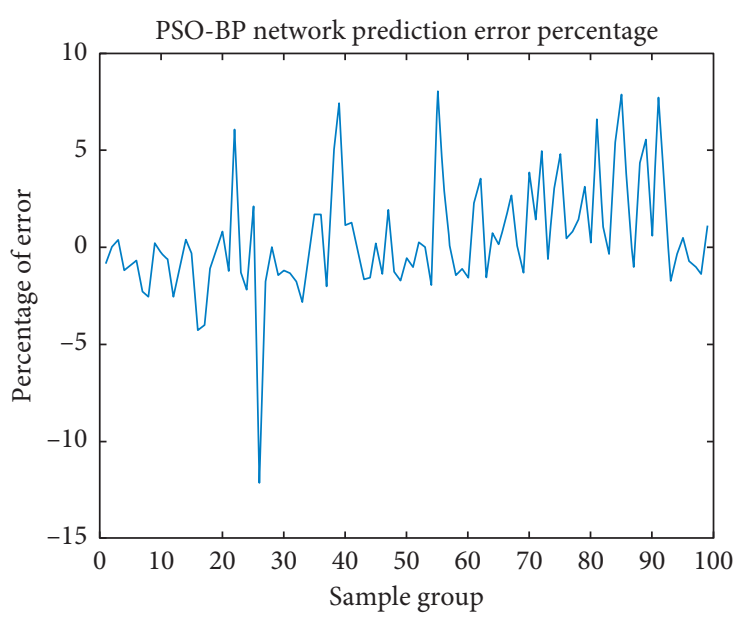

(d)

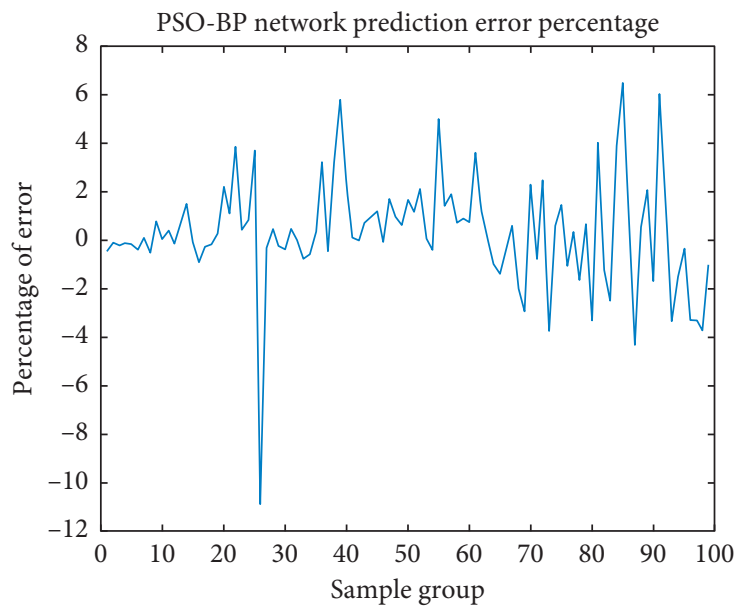

(f)

FIGURE 5: Prediction results and error analysis of nitrogen, phosphorus, and potassium fertilizer application rates in the PSO-BP model.

prediction situation and error percentage of tree fertilization.

It can be seen from Figures $4-6$ that the basic BPNN model can only predict the change level of forest fertilization amount and not accurately predict the actual fertilization amount, the accuracy is poor, the error range is about $20 \%$, and the PSO-BPNN model predicts the amount of forest fertilization. The accuracy is obviously improved, the error between predicted fertilization amount and actual fertilization amount is reduced, and the error range is about $10 \%$, which indicates that the optimization of PSO algorithm has a great influence on accurately predicting the amount of forest fertilization; the main influencing factors of determining the amount of forest fertilization by using grey correlation analysis method. After that, the GRA-PSO-BP prediction model of this paper further enhances the ability to predict the amount of forest fertilization. The predicted value of the GRA-PSO-BP neural network model has small fluctuations near the actual value. The model has a good prediction effect. The error between the predicted fertilization amount and the actual fertilization amount is within 5\%, which can reflect the different forests. The change in nutrient demand during the growth phase can well guide the staged precision fertilization.

The three models were used to predict the nitrogen, phosphorus, and potassium fertilizer application rates of 8 experimental sites and compared with the actual fertilization use. The results are shown in Table 5.

It can be seen from Table 5 that the error percentage between the predicted fertilization amount and the actual fertilization use amount of the GRA-PSO-BP prediction model is the smallest and the error is within 5\%. The prediction accuracy of the GRA-PSO-BP prediction model is better than other fertilization models. The prediction accuracy is high, the error between the predicted fertilization amount and the actual fertilization usage is small, and the 

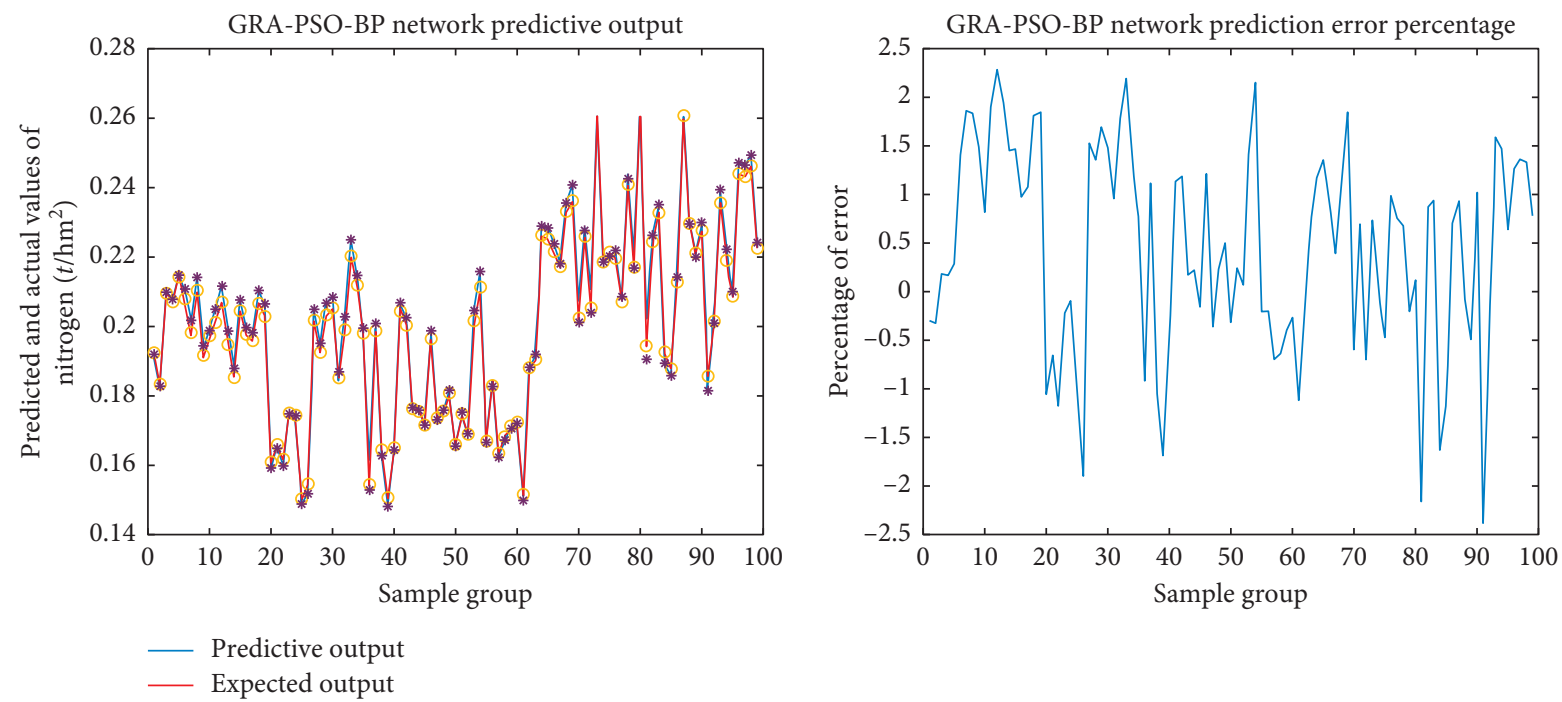

(a)

(b)
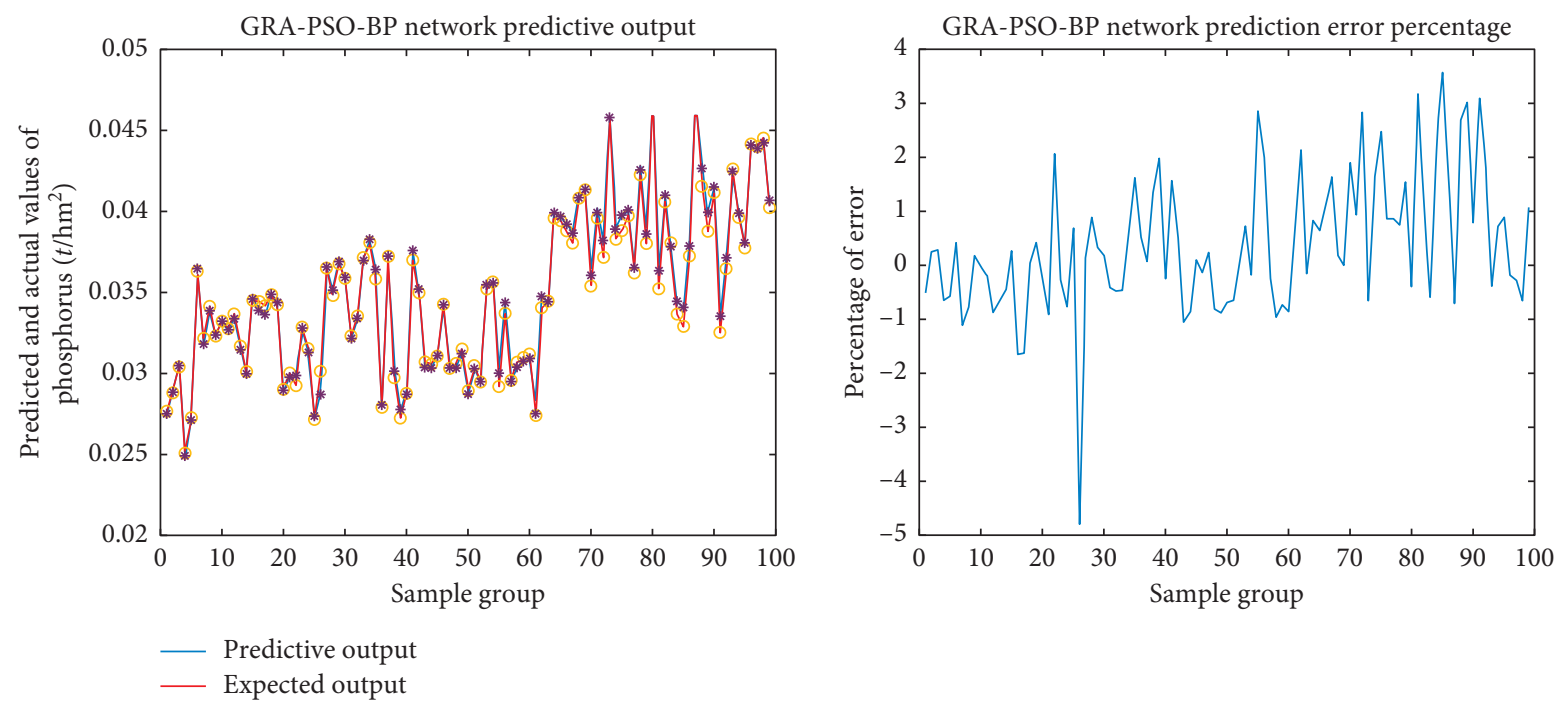

(c)

(d)
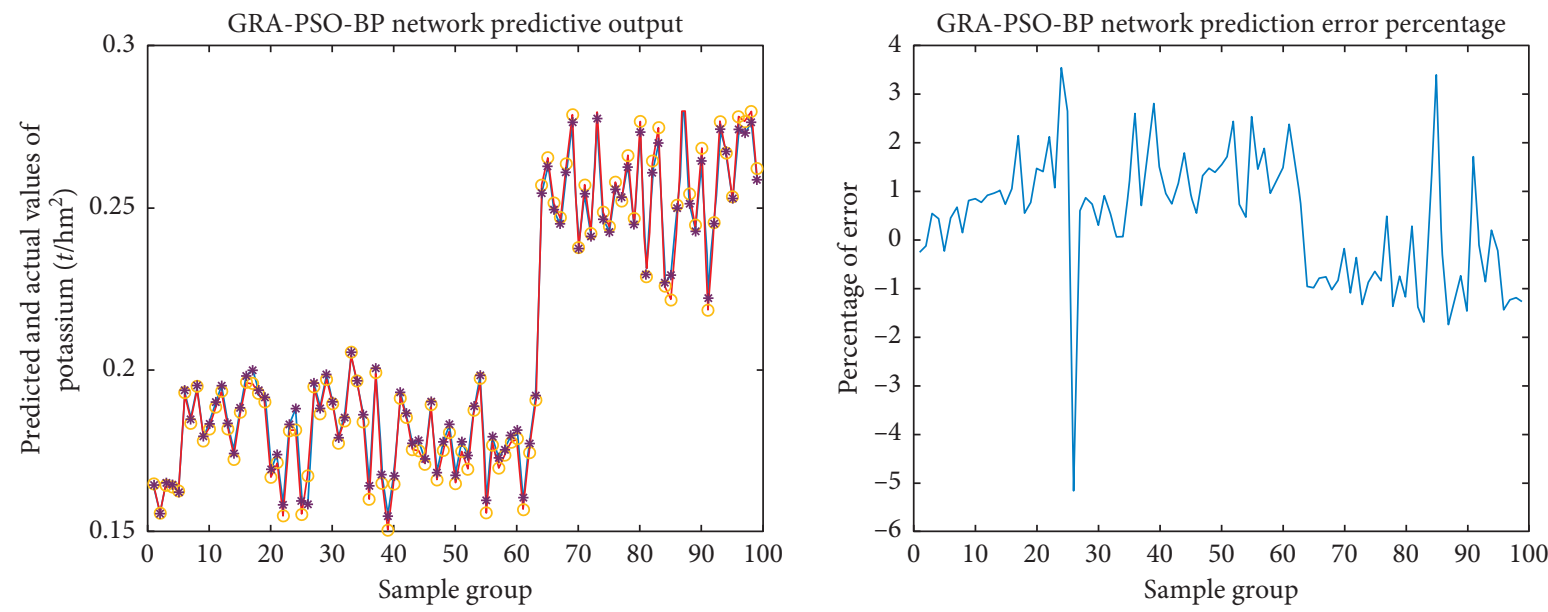

- Predictive output

- Expected output

(e)

(f)

FIGURE 6: Prediction results and error analysis of nitrogen, phosphorus, and potassium fertilizer application rates in GRA-PSO-BP model. 
TABLE 5: Comparison of measured results with predicted results $\left(\mathrm{kg} / \mathrm{hm}^{2}\right)$.

\begin{tabular}{|c|c|c|c|c|c|c|c|c|c|}
\hline Number & $\begin{array}{l}\text { Stand age } \\
(t / a)\end{array}$ & $\begin{array}{c}\text { Site } \\
\text { index } S\end{array}$ & $\begin{array}{l}\text { Actual amount of } \\
\text { nitrogen fertilizer }\end{array}$ & $\mathrm{BP}$ & $\begin{array}{l}\text { Percentage of } \\
\text { error }(\%)\end{array}$ & $\begin{array}{l}\text { PSO- } \\
\text { BP }\end{array}$ & $\begin{array}{l}\text { Percentage of } \\
\text { error }(\%)\end{array}$ & $\begin{array}{l}\text { GRA- } \\
\text { PSO-BP }\end{array}$ & $\begin{array}{l}\text { Percentage of } \\
\text { error (\%) }\end{array}$ \\
\hline 1 & $5 a$ & 5 & 17.38 & 16.31 & 6.551 & 17.67 & 1.66 & 17.35 & 0.1752 \\
\hline 2 & $18 \mathrm{a}$ & 19 & 84.19 & 92.22 & 8.706 & 86.84 & 3.142 & 84.32 & 0.155 \\
\hline 3 & $21 \mathrm{a}$ & 22 & 218.1 & 200 & 9.082 & 217.3 & 0.3702 & 218.3 & 0.0666 \\
\hline 4 & $23 a$ & 25 & 202.3 & 219 & 7.628 & 203.3 & 0.4784 & 201 & 0.6684 \\
\hline 5 & $5 \mathrm{a}$ & 5 & 14.94 & 16.32 & 8.416 & 15.08 & 0.9074 & 14.95 & 0.0589 \\
\hline 6 & $18 \mathrm{a}$ & 19 & 119.9 & 130.5 & 8.12 & 124.6 & 3.876 & 120 & 0.0650 \\
\hline 7 & $21 \mathrm{a}$ & 22 & 216.5 & 199.3 & 8.605 & 214.6 & 0.8908 & 216.4 & 0.0367 \\
\hline 8 & $23 a$ & 25 & 207 & 222.1 & 6.79 & 209.9 & 1.402 & 209.1 & 1.02 \\
\hline 1 & $5 a$ & 5 & 1.609 & 1.794 & 10.32 & 1.649 & 2.45 & 1.611 & 0.1245 \\
\hline 2 & $18 \mathrm{a}$ & 19 & 9.811 & 10.85 & 9.558 & 9.659 & 1.552 & 9.818 & 0.0637 \\
\hline 3 & $21 \mathrm{a}$ & 22 & 28.55 & 30.71 & 7.027 & 28.91 & 1.278 & 28.4 & 0.705 \\
\hline 4 & $23 a$ & 25 & 39.58 & 43.12 & 8.206 & 39.75 & 0.4255 & 39.88 & 0.7471 \\
\hline 5 & $5 a$ & 5 & 1.404 & 1.501 & 6.442 & 1.381 & 1.634 & 1.394 & 0.7023 \\
\hline 6 & $18 \mathrm{a}$ & 19 & 14.91 & 13.78 & 8.236 & 14.84 & 0.5151 & 14.92 & 0.0377 \\
\hline 7 & $21 \mathrm{a}$ & 22 & 24.94 & 27.45 & 9.125 & 24.9 & 0.1747 & 24.74 & 0.8051 \\
\hline 8 & $23 a$ & 25 & 39.73 & 42.93 & 7.444 & 39.84 & 0.2619 & 39.45 & 0.6993 \\
\hline 1 & $5 a$ & 5 & 7.41 & 6.744 & 9.874 & 7.397 & 0.1693 & 7.388 & 0.2956 \\
\hline 2 & $18 \mathrm{a}$ & 19 & 111 & 104.1 & 6.643 & 110.6 & 0.3362 & 110.2 & 0.664 \\
\hline 3 & $21 \mathrm{a}$ & 22 & 155.9 & 162 & 5.541 & 155.8 & 0.07406 & 155.5 & 0.3252 \\
\hline 4 & $23 a$ & 25 & 237.9 & 253.8 & 6.257 & 241.6 & 1.557 & 235 & 1.212 \\
\hline 5 & $5 a$ & 5 & 8.045 & 7.483 & 7.514 & 8.039 & 0.07832 & 8.035 & 0.1311 \\
\hline 6 & $18 \mathrm{a}$ & 19 & 87.88 & 93.75 & 6.267 & 91.21 & 3.791 & 87.9 & 0.0249 \\
\hline 7 & $21 \mathrm{a}$ & 22 & 172.8 & 183.4 & 5.767 & 172.6 & 0.08186 & 173 & 0.1017 \\
\hline 8 & $23 a$ & 25 & 281.2 & 261.8 & 7.395 & 269.1 & 4.289 & 283.2 & 0.7244 \\
\hline
\end{tabular}

generalization performance is good. The model can fully describe the mapping relationship between input and output. According to the target production requirements of Chinese fir forest biomass, the practical amount of nitrogen, phosphorus, and potassium fertilizers can be predicted, which can guide the staged precision fertilization.

On the basis of the above data of actual fertilizer application of nitrogen, phosphorus, and potassium and predicted fertilizer application of nitrogen, phosphorus, and potassium, the paper calculated the mean square error between fertilization prediction results and expected values of different neural network algorithms, different absolute error values, and correlations one by one. The formula for calculating the mean square error is shown in (19). Besides the paper also compared the error and correlation to analyze the traditional BP Neural Network, BP Neural Network that was optimized by PSO algorithm, and the BP Neural Network Prediction Model that was optimized by GRA-PSO algorithm:

$$
\sigma=\sqrt{\frac{\varepsilon_{1}^{2}+\varepsilon_{2}^{2}+\cdots+\varepsilon_{n}^{2}}{n} .}
$$

In the formulation, $n$ represents the number of calculated mean square error data, $\varepsilon_{1}, \varepsilon_{2}, \ldots, \varepsilon_{n}$ indicates the difference between the actual fertilizer application amount of nitrogen, phosphorus, and potassium and the predicted fertilizer application amount of nitrogen, phosphorus, and potassium and $\sigma$ means the square error.

Tables 6-8 show the prediction models which are the traditional BP Neural Network, BP Neural Network that was optimized by PSO algorithm, and the BP Neural Network that was optimized by GRA-PSO algorithm, which predict the correlation and error value between the predicted fertilizer application of nitrogen, phosphorus, and potassium and the actual fertilizer application rate of nitrogen, phosphorus, and potassium.

According to the data in above table, the mean square error of nitrogen, phosphorus, and potassium fertilizer of traditional BP neural network are 12.797; 2.1253; and 10.37. In these data, the maximum absolute errors are $18.1 ; 3.54$; and 19.4. The minimum absolute errors are 1.07; 0.097; and 0.561 , The average absolute errors are $11.02 ; 1.732$; and 8.243 , The correlation numbers are $0.9881 ; 0.9986$; and 0.9939. The mean square error of nitrogen, phosphorus, and potassium fertilizer of BP Neural Network that was optimized by PSO algorithm are 2.3151; 0.1590; and 4.6287. In these data, the maximum absolute errors are 4.7; 0.36; and 12.1. The minimum absolute errors are $0.14 ; 0.023$; and 0.006 . The average absolute errors are $1.797 ; 0.121$; and 2.481 . The correlation numbers are $0.9997 ; 0.9999$; and 0.9989 . The mean square error of nitrogen, phosphorus, and potassium fertilizer of the BP Neural Network that was optimized by GRA-PSO algorithm are $0.8787 ; 0.1699$; and 1.2870 . In these data, the maximum absolute errors are $2.1 ; 0.3$; and 2.9. The minimum absolute errors are $0.01 ; 0.002$; and 0.01 . The average absolute errors are $0.496 ; 0.119$; and 0.794 . The correlation numbers are 0.9999; 0.9999; and 0.9999 .

Through the error value and correlation between the predicted results of $\mathrm{N}, \mathrm{P}$, and $\mathrm{K}$ fertilizer amount and the actual fertilization amount, it can be seen that the prediction accuracy of predication mode of BP neural network 
TABLE 6: Correlation and error value of three models for predicting nitrogen fertilizer.

\begin{tabular}{|c|c|c|c|c|c|}
\hline Fertilization model & $\begin{array}{l}\text { Mean square } \\
\text { error }\end{array}$ & $\begin{array}{l}\text { Maximum absolute } \\
\text { error }\end{array}$ & $\begin{array}{l}\text { Minimum absolute } \\
\text { error }\end{array}$ & $\begin{array}{l}\text { Mean absolute } \\
\text { error }\end{array}$ & Correlation \\
\hline Traditional BP neural network & 12.797 & 18.1 & 1.07 & 11.02 & 0.9881 \\
\hline $\begin{array}{l}\text { BP neural network optimized by PSO } \\
\text { algorithm }\end{array}$ & 2.3151 & 4.7 & 0.14 & 1.797 & 0.9997 \\
\hline $\begin{array}{l}\text { BP neural network optimized by GRA- } \\
\text { PSO algorithm }\end{array}$ & 0.8787 & 2.1 & 0.01 & 0.496 & 0.9999 \\
\hline
\end{tabular}

TABLE 7: Correlation and error value of three models for predicting phosphorus fertilizer.

\begin{tabular}{|c|c|c|c|c|c|}
\hline Fertilization model & $\begin{array}{l}\text { Mean square } \\
\text { error }\end{array}$ & $\begin{array}{l}\text { Maximum absolute } \\
\text { error }\end{array}$ & $\begin{array}{l}\text { Minimum absolute } \\
\text { error }\end{array}$ & $\begin{array}{l}\text { Mean absolute } \\
\text { error }\end{array}$ & Correlation \\
\hline Traditional BP neural network & 2.1253 & 3.54 & 0.097 & 1.732 & 0.9986 \\
\hline $\begin{array}{l}\text { BP neural network optimized by PSO } \\
\text { algorithm }\end{array}$ & 0.1590 & 0.36 & 0.023 & 0.121 & 0.9999 \\
\hline $\begin{array}{l}\text { BP neural network optimized by GRA- } \\
\text { PSO algorithm }\end{array}$ & 0.1699 & 0.3 & 0.002 & 0.119 & 0.9999 \\
\hline
\end{tabular}

TABLE 8: Correlation and error value of three models for predicting potassium fertilizer.

\begin{tabular}{|c|c|c|c|c|c|}
\hline Fertilization model & $\begin{array}{l}\text { Mean square } \\
\text { error }\end{array}$ & $\begin{array}{l}\text { Maximum absolute } \\
\text { error }\end{array}$ & $\begin{array}{l}\text { Minimum absolute } \\
\text { error }\end{array}$ & $\begin{array}{l}\text { Mean absolute } \\
\text { error }\end{array}$ & Correlation \\
\hline Traditional BP neural network & 10.377 & 19.4 & 0.561 & 8.243 & 0.9939 \\
\hline $\begin{array}{l}\text { BP neural network optimized by PSO } \\
\text { algorithm }\end{array}$ & 4.6287 & 12.1 & 0.006 & 2.481 & 0.9989 \\
\hline $\begin{array}{l}\text { BP neural network optimized by GRA- } \\
\text { PSO algorithm }\end{array}$ & 1.2870 & 2.9 & 0.01 & 0.794 & 0.9999 \\
\hline
\end{tabular}

optimized by GRA-PSO algorithm is the best. However, the 8 groups of experimental data are only a small part of the test set. And the poor data sampling may achieve the best predication accuracy of the BP neural network model optimized by the GRA-PSO algorithm. To assure the best predication accuracy of the the BP neural network model optimized by the GRA-PSO algorithm under the maximum probability, the probability of significant difference between BP neural network model and PSO-BP neural network model and that between the PSO-BP neural network model and the BP neural network prediction model optimized by the GRA-BP algorithm must be calculated. DM test provides a calculation method from the perspective of statistics.

The following are the specific methods of DM test.

Because three different algorithms predict models in the span of $T=8$, the error sequence of predicted and actual values of BP network prediction model, PSO-BP network prediction model, and GRA-PSO optimized BP network prediction model are calculated on the span of $T=8$, respectively:

$$
\begin{aligned}
& E_{a}=\left[a^{1}, a^{2}, \ldots, a^{T}\right], \\
& E_{b}=\left[b^{1}, b^{2}, \ldots, b^{T}\right], \\
& E_{c}=\left[c^{1}, c^{2}, \ldots, c^{T}\right] .
\end{aligned}
$$

Next, calculate the difference sequence $D_{a b}=\left[d_{a b}^{1}, d_{a b}^{2}\right.$, $\left.\ldots, d_{a b}^{T}\right], \quad D_{b c}=\left[\begin{array}{llll}d_{b c}^{1}, & d_{b c}^{2}, \ldots, & d_{b c}^{T}\end{array}\right]$, where $d_{a b}^{i}=a^{i}-b^{i}$, $d_{b c}^{i}=b^{i}-c^{i}$.

Finally, the mean and standard deviation of $D_{a b}$ and $D_{a b}$ are calculated, and DM statistics are calculated. The formulas are as follows:

$$
\begin{aligned}
d_{(a b, b c) \text { mean }} & =\frac{\sum_{i=1}^{T} d_{(a b, b c)}{ }^{i}}{T}, \\
d_{(a b, b c) \text { std }} & =\sqrt{\frac{\sum_{i=1}^{T}\left(d_{(a b, b c)}^{i}-d_{(a b, b c) \text { mean }}\right)^{2}}{T-1}}, \\
\mathrm{DM} & =\frac{d_{(a b, b c) \text { mean }}}{d_{(a b, b c) \text { std }}} .
\end{aligned}
$$

The DM test theory holds that the distribution of DM is in accordance with the requirements of the standard normal distribution. Therefore, by querying the confidence values corresponding to DM in the standard normal distribution table, the confidence values of the significant differences between BP network model and PSO-BP network model and between PSO-BP network model and BP network prediction model optimized by GRA-PSO algorithm can be obtained while the predication of the fertilization amount of nitrogen, phosphorus, and potassium is advancing. It is shown in the results that when predicting the fertilization amount of 
nitrogen, phosphorus, and potassium, the confidence values with significant differences between BP network model and PSO-BP network model and between PSO-BP network model and BP network prediction model optimized by GRA-PSO algorithm are 53\%, 68\%; 81\%, 64\%; 61\%, and 53\%, while due to the smallest prediction errors of BP network prediction model optimized by the GRA-PSO algorithm, it enjoys the highest accuracy and the best effect.

The prediction data of the network training are limited, so the different trained fertilization models are timeliness and regionality, while as for this research, because it is on the basis of the annual forest data that was updated by artificial forest and adopted the Analysis method of Grey Relational degree to analyze the key factors of fertilizer application amount in different areas, this can make the precision fertilization come true. After comparing these three prediction algorithms, the result came out that the square error, maximum absolute error, minimum absolute error, and average absolute error numbers of the BP Neural Network that were optimized by GRA-PSO algorithm are small, while the correlation number of it is large, so that the accuracy rate of the BP Neural Network that was optimized by GRA-PSO algorithm is high, and the square error, maximum absolute error, minimum absolute error, and average absolute error numbers of the traditional BP Neural Network and BP Neural Network that were optimized by PSO algorithm are relatively large, but the correlation number is relatively small, which draws the conclusion that the accuracy rate of these two prediction methods is relatively low.

\section{Conclusions}

It is inefficient to determine the amount of fertilization by traditional experience or basic theoretical model, which may also cause environmental pollution, so it is difficult to adapt to the new situation of precision forestry advocated by the contemporary world. As the current application of sensor network is getting more diversified, data acquisition in forest area is easier than before. Through real-time data update, real-time prediction can be carried out using high-tech to build fertilizer model. But different fertilization models will have timeliness and regionality. In different forest ecological areas, it seems to be impossible to accurately make a prediction at present using the definite fertilization model with an eye to different factors that affect the precision fertilization of trees.

The traditional methods to determine the amount of fertilizer application are empirical method, fertilizer effect function method, and nutrient balance method. The empirical method means that forest farmers fertilize trees on their willing which is according to their experience and without basis. This method is simple and sometimes feasible, but in most cases, it is not accurate enough, which often results in insufficient or excessive fertilizer application and make it not fit the needs of high yield and efficiency of forestry construction. The fertilizer effect function method needs a lot of experimental data, but the successful rate of the fitting is not high, and a lot of data resources are just wasted, so that a lot of financial wealth, material, and human labors are wasted too. The nutrient balance method often needs to come up with expert experience, because it requires too many parameters and also there is a relative error in the calculation of fertilization. It is important to find an effective and accurate fertilization model. Artificial neural network has a strong ability to solve nonlinear problems. In order to solve the problem of nonlinear precision fertilization, this paper introduces the neural network modeling method and uses BPNN, PSO-BPNN, and GRA-PSO-BPNN to construct three kinds of forest precise fertilization models for comparative verification and result analysis. Through comparison, the accuracy of the BPNN model is low and the error range is about $20 \%$, and it is unstable. Although the PSOBPNN model has high accuracy, the error range is about $10 \%$, considering that the fertilization model mentioned above is time-sensitive and regional, the factors that may affect the fertilization are different in different time and different regions. In some geographically complex areas, more factors need to be considered to ensure accurate fertilization. Since it is difficult for the PSO-BPNN model to identify the key influencing factors of forest fertilizer application in different regions, the PSO-BPNN model has poor scalability. However, the key factors influencing forest fertilizer application in different regions can be determined by grey relational analysis. The constructed GRA-PSOBPNN forest tree precision fertilization model not only has high accuracy, the error range is about $5 \%$, and it has a faster calculation speed, but also applicable to the determination of forest fertilizer application in different regions and can constantly update the forest fertilizer model with good expansibility.

\section{Discussion}

With the in-depth development of modern forestry, precision forestry is receiving unprecedented attention. The emergence of forest precise fertilization model will greatly promote the forestry production. Forest economy plays an important role in the society improvement, and to improve the forest economy, only the development of artificial fastgrowing and high-yielding forest can be depended, and the effective way to improve the productivity of artificial forest is just precision fertilization. The prediction of precision fertilization is a scientific and innovative technology which can achieve five goals: ensuring high quality, increasing the production, improving soil quality and ecology, and high efficiency; taking the factors which affect the amount of fertilizer application as the basis and making the fertilizer application rate and fertilization target clear before implementing it; linking the fertilization with economic benefit; achieving the quantitative fertilization of forest trees under the realization of target benefit, making a prediction of the benefit that earned by the fertilization, and according to the investigation of basic data and soil chemical analysis in forest area, so that the ratio of tree fertilization under the target benefit can be calculated; making forest fertilization become an important safeguard measure to improve the quality and yield of commercial forest. At the same time, as a direction of precision forestry technology, precision fertilization model 
will attract more and more attention of forestry science and technology personnel and forestry production managers. In this paper, the GRA-PSO-BPNN prediction model of forest periodic precise fertilization is of far-reaching significance to solve the problem of forest fertilization that has been troubling people for a long time, which can be applied by forest-related workers in forestry ecological zones where conditions are basically the same. If the generalization is carried out in a larger and more complex area to improve the generalization ability of the model, it is necessary to consider other factors affecting the amount of forest fertilization, such as soil type, organic matter, $\mathrm{pH}$, and other factors. In some cases, the GRA-PSO-BPNN precise fertilization model for trees may need to be updated based on the experience of experts, which is what needs to be further studied.

\section{Data Availability}

The raw/processed data required to reproduce these findings cannot be shared at this time as the data also forms part of an ongoing study.

\section{Conflicts of Interest}

The authors declare no conflicts of interest.

\section{Authors' Contributions}

Chen Zuxing and Wang Dian contributed analytical tools and ideas, collected and processed the data, conducted experiments and wrote papers, and finally finalized the final version of the paper.

\section{Acknowledgments}

This work was supported by the Central University's Basic Research Project (2016ZCQ08).

\section{References}

[1] T. Cao, L. Valsta, S. Härkönen, P. Saranpää, and A. Mäkelä, "Effects of thinning and fertilization on wood properties and economic returns for Norway spruce," Forest Ecology and Management, vol. 256, no. 6, pp. 1280-1289, 2008.

[2] T. Pukkala, "Optimal nitrogen fertilization of boreal conifer forest," Forest Ecosystems, vol. 4, 2017.

[3] J. Bergh, U. Nilsson, H. L. Allen, U. Johansson, and N. Fahlvik, "Long-term responses of scots pine and Norway spruce stands in Sweden to repeated fertilization and thinning," Forest Ecology and Management, vol. 320, pp. 118-128, 2014.

[4] P.-O. Hedwall, P. Gong, M. Ingerslev, and J. Bergh, "Fertilization in northern forests-biological, economic and environmental constraints and possibilities," Scandinavian Journal of Forest Research, vol. 29, no. 4, pp. 301-311, 2014.

[5] W. X. Hu Yueli, Research on Fertilization of Forest Trees-I: Fertilization Theory and Basic Models, Zhongnanlin University, Wuhan, China, 1994.

[6] W. X. Hu Yueli, Study on Dynamic Model of Forest Growth and Nutrient v: Nutrient Curve of Chinese fir Forest, Zhongnan Forestry College, Zhongnan, China, 1999.

[7] W. X. Wu Lichao, B. Wang, J. Wu, Z. Li, and M. Lu, "Research progress in fast-growing and high-yield fertilization techniques of Paulownia," Central South University of Forestry and Technology, vol. 30, pp. 29-35, 2010.

[8] H. Y. Wu Xiaofu, "Study on fertilization of forest trees-application of II fertilization model in Chinese fir forest," Zhongnan Forestry College, Zhongnan, China, 1995.

[9] H. Y. Wu Xiaofu, Study on the Growth and Nutrition Dynamic Model of Forest Trees-Formed Fertilization Model of Site Nutrient Effect, Zhongnanlin University, Zhongnanlin, China, 2002.

[10] L. L. Bhering, C. D. Cruz, L. D. A. Peixoto, A. M. Rosado, B. G. Laviola, and M. Nascimento, "Application of neural networks to predict volume in eucalyptus," Crop Breeding and Applied Biotechnology, vol. 15, no. 3, pp. 125-131, 2015.

[11] S. Che, X. Tan, C. Xiang et al., "Stand basal area modelling for Chinese fir plantations using an artificial neural network model," Journal of Forestry Research, vol. 30, no. 5, pp. 1641-1649, 2019.

[12] M. J. Diamantopoulou and E. Milios, "Modelling total volume of dominant pine trees in reforestations via multivariate analysis and artificial neural network models," Biosystems Engineering, vol. 105, no. 3, pp. 306-315, 2010.

[13] R. Özçelik, J. R. Diamantopoulou, and H. V. Wiant, "Estimating tree bole volume using artificial neural network models for four species in Turkey," Journal of Environmental Management, vol. 91, no. 3, pp. 742-753, 2010.

[14] C. O. Sabatia and H. E. Burkhart, "Predicting site index of plantation loblolly pine from biophysical variables," Forest Ecology and Management, vol. 326, pp. 142-156, 2014.

[15] A. A. Vahedi, "Monitoring soil carbon pool in the hyrcanian coastal plain forest of Iran: artificial neural network application in comparison with developing traditional models," Catena, vol. 152, pp. 182-189, 2017.

[16] J. Xiong, T. Cui, and N. Mao, "Grey correlation analysis on the total health expenditure structure and per capita medical expenses in China," Value in Health, vol. 21, 2018.

[17] W. Xiong, L. Liu, and M. Xiong, "Application of gray correlation analysis for cleaner production," Clean Technologies and Environmental Policy, vol. 12, no. 4, pp. 401-405, 2010.

[18] P. Zhou, Y.-J. Yao, Y.-F. Ai, A.-M. Liu, Z.-L. Xu, and J.-C. Xie, "Grey correlation analysis of factors influencing maldistribution in feeding device of copper flash smelting," Journal of Central South University, vol. 19, no. 7, pp. 1938-1945, 2012.

[19] W. Zhang, Y. Yu, X. Zhou, S. Yang, and C. Li, "Evaluating water consumption based on water hierarchy structure for sustainable development using grey relational analysis: case study in Chongqing, China," Sustainability, vol. 10, no. 5, p. 1538, 2018.

[20] T. Bai, H. Meng, and J. Yao, "A forecasting method of forest pests based on the rough set and PSO-BP neural network," Neural Computing and Applications, vol. 25, no. 7-8, pp. 1699-1707, 2014.

[21] Z. Cheng, X. Li, Y. Bai, and C. Li, "Multi-scale fuzzy inference system for influent characteristic prediction of wastewater treatment," Clean-Soil, Air, Water, vol. 46, no. 7, Article ID 1700343, 2018.

[22] A. Ismail, D.-S. Jeng, and L. L. Zhang, "An optimised productunit neural network with a novel PSO-BP hybrid training algorithm: applications to load-deformation analysis of axially loaded piles," Engineering Applications of Artificial Intelligence, vol. 26, no. 10, pp. 2305-2314, 2013.

[23] X. Y. Liang, Z. Yang, X. S. Gu, and L. C. Ling, "Research on activated carbon supercapacitors electrochemical properties based on improved PSO-BP neural network," CMC-Computers Materials \& Continua, vol. 13, pp. 135-151, 2009. 
[24] C. Ren, N. An, J. Wang, L. Li, B. Hu, and D. Shang, "Optimal parameters selection for BP neural network based on particle swarm optimization: a case study of wind speed forecasting," Knowledge-Based Systems, vol. 56, pp. 226-239, 2014.

[25] C. Sudheer and S. Mathur, "Particle swarm optimization trained neural network for aquifer parameter estimation," KSCE Journal of Civil Engineering, vol. 16, pp. 298-307, 2012.

[26] T. Liu and S. Yin, "An improved particle swarm optimization algorithm used for BP neural network and multimedia courseware evaluation," Multimedia Tools and Applications, vol. 76, no. 9, pp. 11961-11974, 2017.

[27] I. Sutrisno, M. Abu Jami'in, and J. Hu, “An improved elman neural network controller based on quasi-arx neural network for nonlinear systems," IEEJ Transactions on Electrical and Electronic Engineering, vol. 9, no. 5, pp. 494-501, 2014.

[28] Y. Deng, H. Xiao, J. Xu, and H. Wang, "Prediction model of PSO-BP neural network on coliform amount in special food," Saudi Journal of Biological Sciences, vol. 26, no. 6, pp. 11541160, 2019.

[29] X. Liu, Z. Liu, Z. W. Liang, S. P. Zhu, J. A. F. O. Correia, and A. M. P. De Jesus, "PSO-BP neural network-based strain prediction of wind turbine blades," Materials, vol. 12, no. 12, 2019.

[30] Y. Mei, J. Q. Yang, Y. Lu et al., "BP-ANN model coupled with particle swarm optimization for the efficient prediction of 2chlorophenol removal in an electro-oxidation system," International Journal of Environmental Research and Public Health, vol. 16, 2019.

[31] S. Zhang and J. Ou, "BP-PSO-based intelligent case retrieval method for high-rise structural form selection," Science China Technological Sciences, vol. 56, no. 4, pp. 940-944, 2013. 